\title{
Aligned carbon nanotube-epoxy composites: the effect of nanotube organization on strength, stiffness, and toughness
}

\author{
Anastasiia Mikhalchan ${ }^{1}$, Thurid Gspann ${ }^{1}$, and Alan Windle $e^{1, *}$ \\ ${ }^{1}$ Macromolecular Materials Laboratory, Department of Materials Science and Metallurgy, University of Cambridge, 27 Charles \\ Babbage Road, Cambridge CB3 OFS, UK
}

Received: 15 April 2016

Accepted: 13 July 2016

Published online:

9 August 2016

(C) 2016. This article is published with open access at Springerlink.com

\begin{abstract}
A protocol has been developed for the production of epoxy-based composites containing high-volume fractions of aligned carbon nanotubes. The nanotubes were fabricated as continuous fibres or aligned mats directly from the CVD reactor, in which they were synthesized. The block composites with highly aligned and tightly packed nanotube assemblies were prepared via epoxy resin infiltration, and their volume fraction, distribution, and internal porosity being analysed prior to mechanical testing. The samples were tested in both axial tension and three-point bending. The results show that the strength and stiffness enhancements were close to pro rata with the volume fraction of the carbon nanotubes added. The failure modes were distinctly different from those characteristic of the conventional aligned carbon fibre composites. The fracture surface showed considerable evidence of pull-out of bundles of $(\sim 50)$ nanotubes, but the pull-out appeared to involve the resin matrix which drew out along with the bundles. Subsidiary cracks were bridged by nanotube bundles giving structures reminiscent of crazes in glassy polymers, what constitutes the distinct toughness mechanism and higher resistance to the transverse cracks propagation.
\end{abstract}

\section{Introduction}

Assemblies of carbon nanotubes have captured attention of many research groups, providing different approaches to exploit the unique properties of individual carbon nanotubes (CNT) in macroscopic materials. Assembling of CNT into fibrous materials has been successfully realized through a range of methods, including wet-spinning technique [1], spinning from their liquid crystalline solutions [2], spinning from dry arrays [3], or direct spinning from the gas phase during the floating catalyst CVD synthesis, as described elsewhere [4, 5]. High-performance carbon nanotube fibres (CNTF) possess high thermal conductivity and outstanding electrical

Address correspondence to E-mail: ahw1@cam.ac.uk 
conductivity able to compete with metals $[1,6]$, and thus they have been recognized as promising materials for cost-effective electronics and electrical wiring [7]. Their potentially high strength and stiffness [8] open up fibre reinforcement in the production of composite materials, as an alternative to high-performance fibres, such as carbon fibre and Kevlar.

The production of carbon nanotube fibres and mats via the floating catalyst CVD method is currently being transferred out of the laboratory into the hands of commercial ventures who are establishing scaled-up process as a precursor to commercial production [9]. It is thus natural to consider CNT fibre (CNTF) as a possible substitute for the other well-established fibres in composites. This structural replacement will require the utilization of prepregs made of CNT fibres, where CNT fibres are aligned and tightly packed before being infiltrated with a resin in a manner similar to the conventional prepregs. While a typical unidirectional carbon fibre prepreg comprises $60-70 \%$ of carbon fibres by volume, the volume fractions for composites reinforced with CNT assemblies being reported are still far lower. For aligned CNT sheets, the highest volume content which has been reached is $20-27 \%$ [10], and most recently $55 \%$ (67\% by weight) [11]. However, for the porous CNT fibres spun directly via the floating catalyst method, a previous study from this laboratory achieved only $22-24 \%$ by volume $[12,13]$.

In this study, we have investigated tensile and flexural properties of the high-volume fraction composites, where the aligned CNT assemblies (fibres and mats) are packed closely together almost without noticeable regions of pure epoxy in between. The structure of the samples was fully characterized prior to testing not only to evaluate volume fraction of the added CNT material, but also to determine the uniformity of distribution of the nanotubes in the composite and to some extent the quality of the orientation. The degree of internal voiding as inferred from density measurements was compared with microscopic observation and in line with our previous observations [12], the epoxy was able to penetrate the CNT fibre and to fill the highly elongated nanovoids between the nanotube bundles. The resin did not, however, penetrate the bundles themselves within which the nanotubes remain packed closely together [14].
The newly determined mechanical data are compared with the available relevant literature for CNTepoxy composite systems containing high-volume fraction of (usually) aligned nanotubes. In addition, we introduce data for samples based on a standard carbon fibre (Toray T300) rather than CNTF, ensuring, as far as possible, that our process protocol for the conventional composite sample was exactly the same as that used for the nanotube assemblies. We note that the fracture mode is distinctly different from that seen in CNT composites, with different energy absorption mechanisms evident in the fracture process, which we discuss in terms of the general issue of toughness. The observed ability of pulled-out nanotube bundles to bridge the significant subsidiary cracks, with openings in the range from several micrometers to $\sim 0.5 \mathrm{~mm}$, suggests a mechanism which may render composites reinforced with CNT fibres tougher in their ability to resist the propagation of transverse cracks.

\section{Materials and methods}

\section{Materials}

Carbon nanotubes were synthesized in a CVD tube reactor under hydrogen atmosphere using toluene as carbon precursor, ferrocene as catalyst, and thiophene to provide the sulfur 'promoter'. The nanotubes were collected as macro-assemblies-either in the form of fibres or mats. For fibres, the CNT aerogel was spun out of the gas phase at rates of $10-30 \mathrm{~m} / \mathrm{min}$ and condensed on-line by atomized acetone, the stage at which the open network of nanotube bundles merges to form a more continuous yarn-like fibre with a uniform cross section (which we refer to as CNT fibre or CNTF). The yarnlike nature of the fibre arises from its composition of $10^{4}$ to $10^{5}$ CNT bundles per cross section, each of which is relatively 'slippery' with respect to its neighbours [15]. During the condensation but prior to epoxy infiltration, about 1000 individual fibres, each with an average tensile strength of $1.16 \mathrm{GPa}$ [16], linear density of 0.03 tex, and $8 \mu \mathrm{m}$ diameter were aligned and wound up together to form 'macro-fibres' (or 'unidirectional tows') of $\sim 200 \mu \mathrm{m}$ diameter. CNT mats (CNTM) were synthesized under the same conditions, but wound up continuously without acetone condensation. 
Composites were made using a hot curing epoxy matrix based on bisphenol A epoxy resin (Araldite LY 1564), anhydride hardener (Aradur 917), and amine accelerator (960-1). The epoxy system is recommended for industrial filament winding, pultrusion, wet lay-up, or Resin Transfer Moulding (RTM) manufacturing processes to produce composites with enhanced mechanical properties. ${ }^{1}$ It combines a low mix viscosity (100-200 $\mathrm{mPa} \cdot \mathrm{s}$ at $\left.40{ }^{\circ} \mathrm{C}\right)$, for efficient penetration into our nanotube material, with a pot life at impregnation temperature of several hours. In line with normal composite practice, $1.5 \%$ wt of a commercially available surfactant (BYK-Chemie $\mathrm{GmbH}$ ) was added to the matrix as an 'air release' agent.

\section{Nanocomposites processing}

The formulated epoxy system was mixed thoroughly to ensure homogeneity at a mix ratio $100 \times 98 \times 3$ (resin $\times$ hardener $\times$ accelerator, $\%$ by weight) as recommended by the supplier, then degassed in a vacuum oven for 30-60 min at $40{ }^{\circ} \mathrm{C}$ before impregnation. Pre-determined amounts of carbon nanotubes, whether in the form of fibres or aligned mats were then, after orientation with respect to the long axis of the custom-built mould, infiltrated with matrix material under pressure at $40{ }^{\circ} \mathrm{C}$, and degassed before curing. All specimens, including the control sample of pure matrix, were cured at the same cycle: $3 \mathrm{~h}$ at $100{ }^{\circ} \mathrm{C}$, then $2 \mathrm{~h}$ at $120^{\circ} \mathrm{C}$ in a vacuum oven, followed by oven cooling to room temperature. Double-sided silicon release paper was used as antiadhesive between sample and mould. All the samples were carefully polished prior to further investigations.

\section{Characterization methods}

TGA thermograms were recorded (TA Instruments Q500) by heating the specimens from room temperature to $700{ }^{\circ} \mathrm{C}$ in a dynamic oxidative atmosphere (air) with a flow rate of $60 \mathrm{~mL} / \mathrm{min}$. These measurements were used to verify weight fractions of the nanotube material in the composites using the protocol described in [12]. The apparent volumetric density of each sample was calculated from its dimensions taken by a digital micrometer and its

\footnotetext{
1 Araldite LY1564/Aradur 917/Accelerator 960-1 datasheet, 30.11.2012 http://www.huntsman.com/advanced_materials.
}

mass measured using high-precision Sartorius microbalance. X-ray micro-tomography (Bruker SkyScan 1172) was used for microstructural characterization and three-dimensional (3-D) visualization (details in supplementary materials, S1). SEM images were obtained with the FEI Nova NanoSEM 450. All specimens were coated with platinum for $1 \mathrm{~min}$ to minimise charging. Cross sections of the CNT fibres and composites were cut using a Focused Ion Beam (FIB) using the Helios FIB/FEG-SEM workstation. The 2D FFT analysis of the SEM images (grayscale 8-bit, cropped to $1024 \times 1024$ pixels) was done with the ImageJ software (developed by the National Institutes of Health) and an oval-profile plug-in (authored by Bill O'Connell) available from the public domain http://rsb.info.nih.gov/ij [17]. Polarized Raman spectra were obtained with a Bruker Senterra Raman microscope using 785-nm excitation (supplementary materials, S2). The maximum intensity ratios of $\mathrm{IG}_{0} / \mathrm{IG}_{90}\left(\mathrm{I}_{\mathrm{VV}} / \mathrm{I}_{\mathrm{HH}}\right.$, with the sample being aligned with the incident beam in $\mathrm{V}$ direction) were each calculated by averaging a map of ten positions.

Three-point bend tests were performed with a Hounsfield test machine model $500 \mathrm{~L}$ with the $250-\mathrm{N}$ load cell, a span-to-depth ratio of 40:1, and a speed rate of $1 \mathrm{~mm} / \mathrm{min}$. Each specimen was deflected until rupture occurred. The load-deflection curves, after removal of the initial 'toe region', were used to determine the flexural strength, strain, and modulus of elasticity according to the ASTM D 7264 standard.

Tensile tests according to the ASTM D7205/ D7205M-06 were obtained using an Instron test machine model $859 \mathrm{i}$ with pneumatic grips, a $100-\mathrm{kN}$ load cell, a test speed of $10 \mathrm{~mm} / \mathrm{min}$, and an initial gauge length of $20 \mathrm{~mm}$. To prevent slipping while avoiding stress concentrations at the grips, both ends of each specimen were glued in between of two Hexlite panels (glass fibre-reinforced honeycomb, Hexcel Ltd.) using an epoxy bi-componential rapid adhesive glue, and held overnight at room temperature under pressure for optimum bonding.

\section{Results}

\section{Carbon nanotube assemblies}

Carbon nanotube fibres and mats were used to compare their reinforcement efficiency for epoxy matrix. Both mats and fibres were composed of 

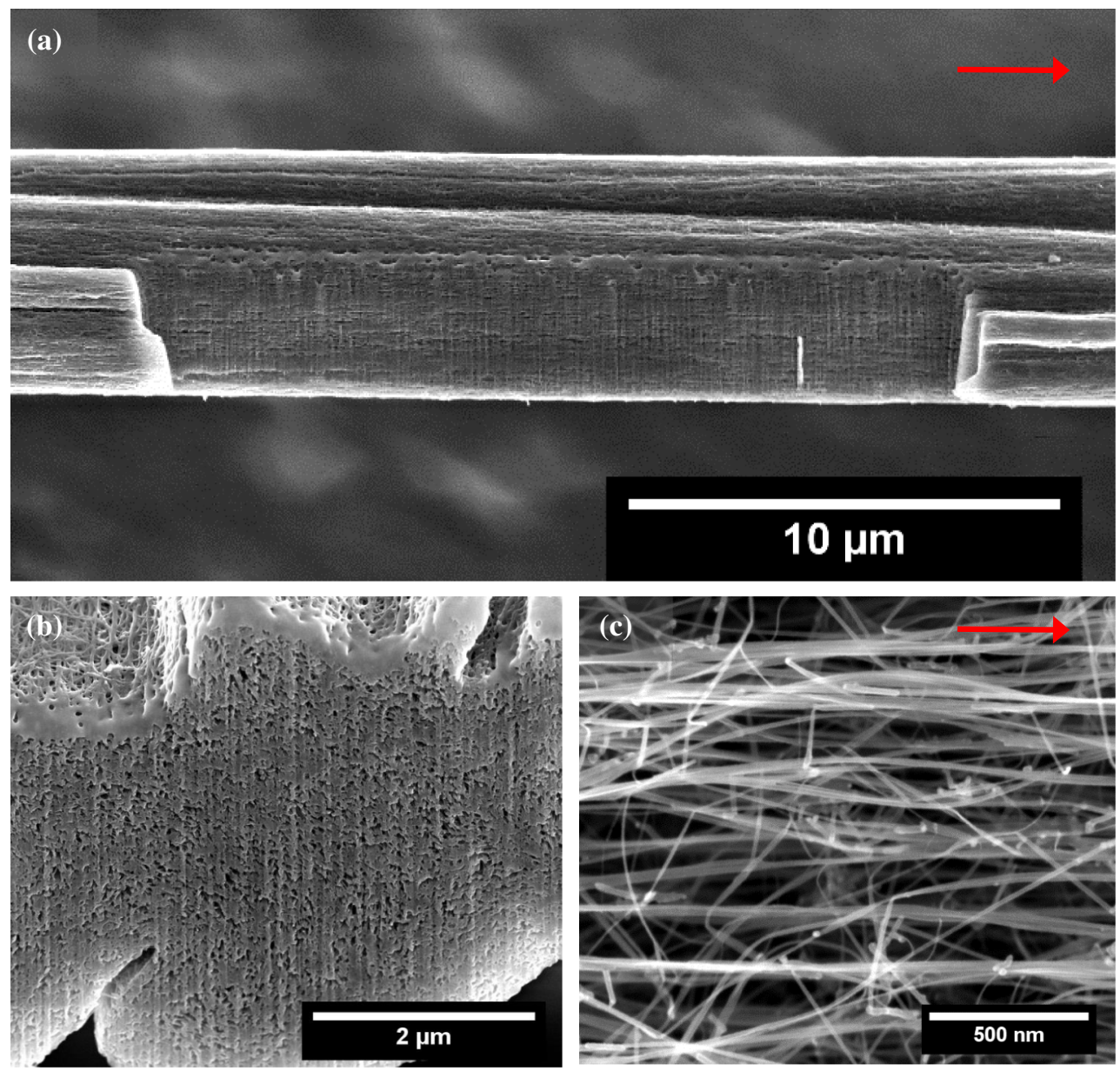

Figure 1 SEM images of CNT assemblies used as reinforcing components of the composites: an individual condensed CNT fibre with its a longitudinal- and $\mathbf{b}$ cross-sectional cut by Focused Ion Beam (FIB); and c uncondensed CNT mat. Red arrows indicate

mostly double-wall nanotubes collapsed and formed into bundles of $40-50 \mathrm{~nm}$ diameter and length of the order of $100 \mu \mathrm{m}$. According to TGA, the residual Fecatalyst varied from 1 to $3.7 \% \mathrm{wt}$ (see supplementary materials, S3). SEM analysis confirmed a high degree of preferred axial orientation of the nanotubes, their overall uniformity, and the absence of any large impurity clusters (Fig. 1).

The longitudinal and cross sections of the fibre (Fig. 1a, b) show that, despite condensation, the structure contains a considerable amount of voids between the nanotube bundles. They are highly elongated and interconnected with the result that the resin penetrates the condensed fibres and fills the voids [12, 13]. The interconnected voids are also confirmed by the specific surface area of the fibre which can be up to $200 \mathrm{~m}^{2} / \mathrm{g}$ depending on the winding direction and bundle orientation. The 'melt-like' top surface edges and the vertical lines on the FIB sections are ion beam cutting artifacts.

synthesis conditions $[4,13,14]$. The oriented CNT mat comprises a far less dense network of laterally entangled aligned nanotube bundles (Fig. 1c). We should emphasize that all CNT mats and fibres were incorporated into the composites as-synthesized and without any further modification by mechanical or chemical post-treatments.

The orientation of CNT bundles within their assemblies can be quite clearly seen from the exemplary SEM images (Fig. 2a, d). For the uncondensed CNT mats, the CNT bundles form a continuous network; however, some types of bundles misalignment are visible, including their local curvature, twisting, loops, or changing direction perpendicularly to join a neighbouring bundle. For the CNT fibres, bundles and inter-bundle pores are mostly oriented in the fibre's axis (synthesis and winding direction), which 

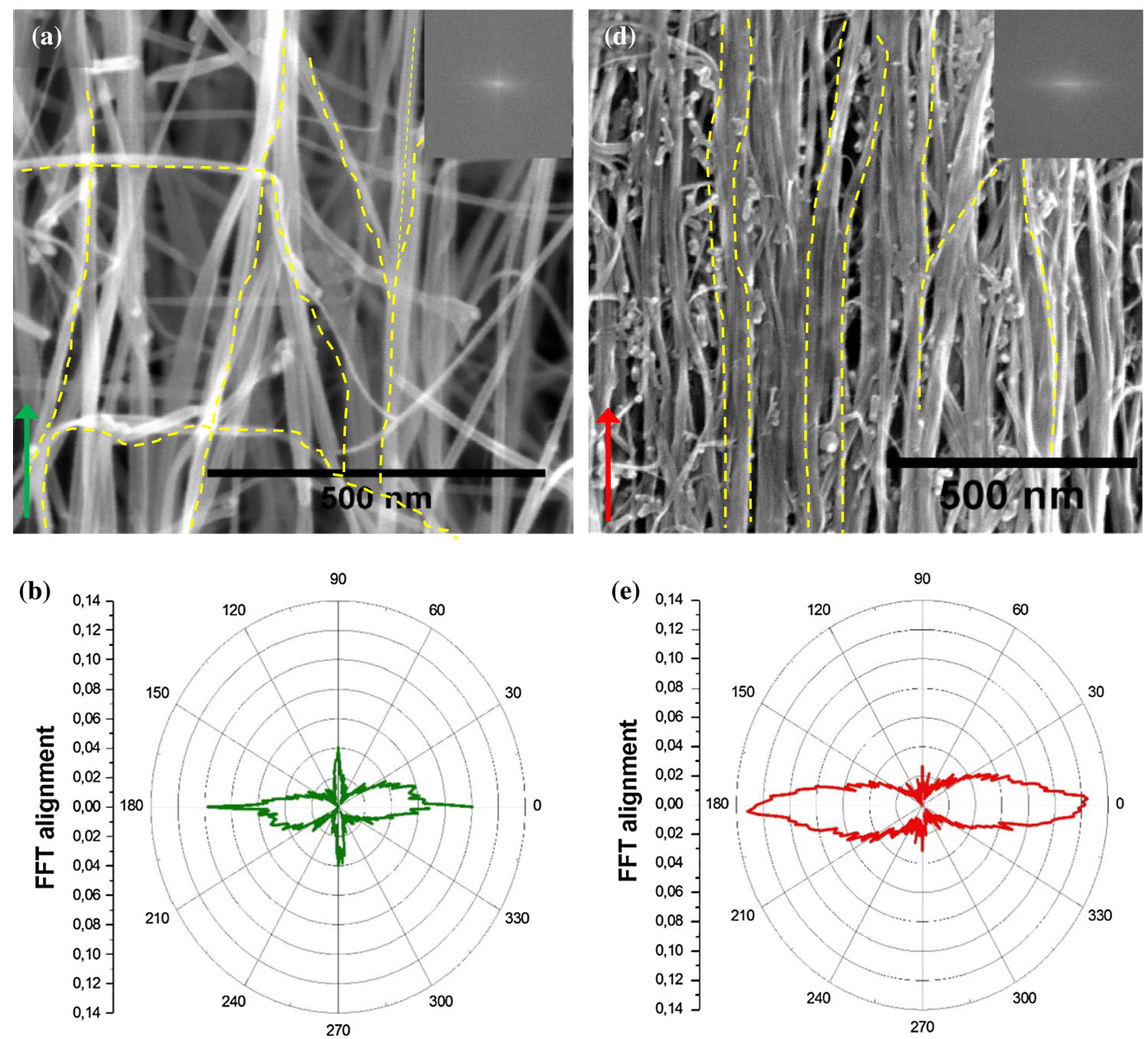

(c)

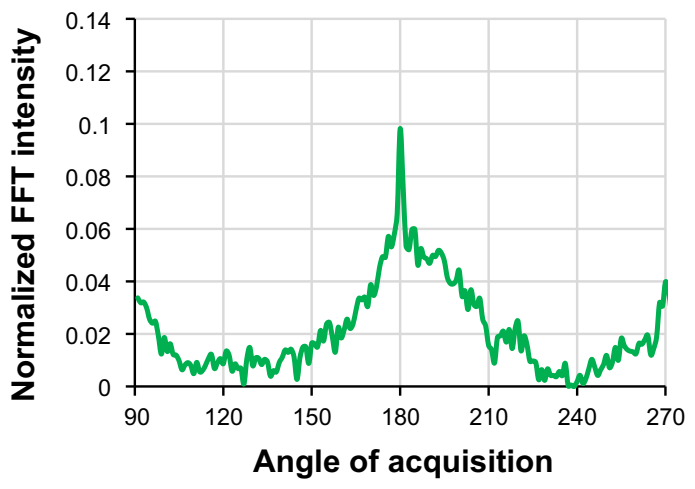

(f)

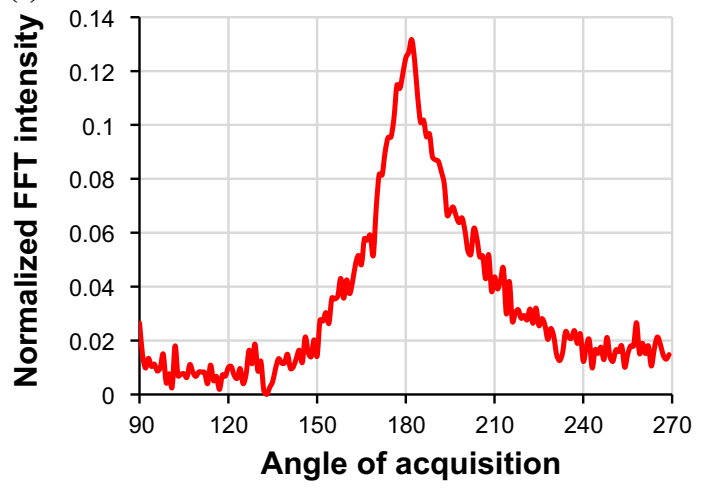

Figure 2 Analysis of the CNT bundles alignment within their assemblies: representative SEM images of a an uncondensed CNT mat, $\mathbf{d}$ top surface of a condensed CNT fibre at high magnification. Scale bars are $500 \mathrm{~nm}$. Yellow dash lines highlight some visible misalignments and local curvature of CNT bundles. Green and red

arrows show the synthesis and winding direction (fibre axis). Corresponding insets to $\mathbf{a}$ and $\mathbf{d}$ are the 2D FFT patterns used for radial integration of pixel intensities $(\mathbf{b}, \mathbf{e})$. c, $\mathbf{f}$ represent the azimuthal scans summed over a range of radii used for the calculation of the first-order spherical harmonic coefficient. 
is visible on both top and longitudinal section surfaces at high magnification. It is obvious that liquid densification causes merging of CNT bundles, enhancing their packing efficiency in the fibre and resulting in local curvature which is less distinct than in the uncondensed CNT mats. The less local curvature (so-called "waviness") was also observed for the vertically aligned CNT arrays upon their mechanical densification [18].

The differences in alignment apparent in the micrographs are quantified using the two-dimensional Fast Fourier Transform (2D FFT) analysis of the representative SEM images. For this purpose, the images were transformed into binary version composed exclusively of black and white pixels, thus reducing the noise effects and spurious information. The FFT patterns (Fig. 2 insets a, d). were then radially integrated to obtain FFT intensity profile as a function of angle of acquisition, I $(\phi)$ (Fig. $2 b, c, e, f)$. The base line of this plot was taken as the minimum recorded value of intensity.

Values of the first even spherical harmonic coefficient were calculated for the cases of CNT fibre and CNT mat from the plots of $I(\phi)$ (Fig. 2c, f). As the harmonic coefficient refers in this case to orientation observed in the plane of the micrograph, whereas its designation as P2 implies cylindrical symmetry the fibre axis, something which certainly cannot be assumed in the case of the mat, we refer to it as the Herman's orientation function, $H$, defined, as for $\mathrm{P} 2$, as:

$H=\frac{3 \cdot<(\phi) \cdot \cos ^{2} \Phi>-1}{2}$

where the diamond brackets denote the average value of the product over equal angular intervals normalized to the average intensity.

It is interesting to note that the fraction of bundles in the mat sample which are not well aligned tends to be at around $90^{\circ}$ to the main alignment axis, indicating that the bundles had been subject to some spreading action possibly during wind up. This population produces the subsidiary peaks, at $\pm 90^{\circ}$ from the main peak (Fig. 2c), which will tend to reduce the value of $H$. The values for $H$ obtained are: mat 0.5 and fibre 0.63 .

The actual value of $\mathrm{H}$ is dependent on the choice of base line. For example, if most of the CNTs had random orientation with only a small sub-set providing the particular distribution, then the values of P2 would have been less. We know that there is no such background from the micrographs, so taking the

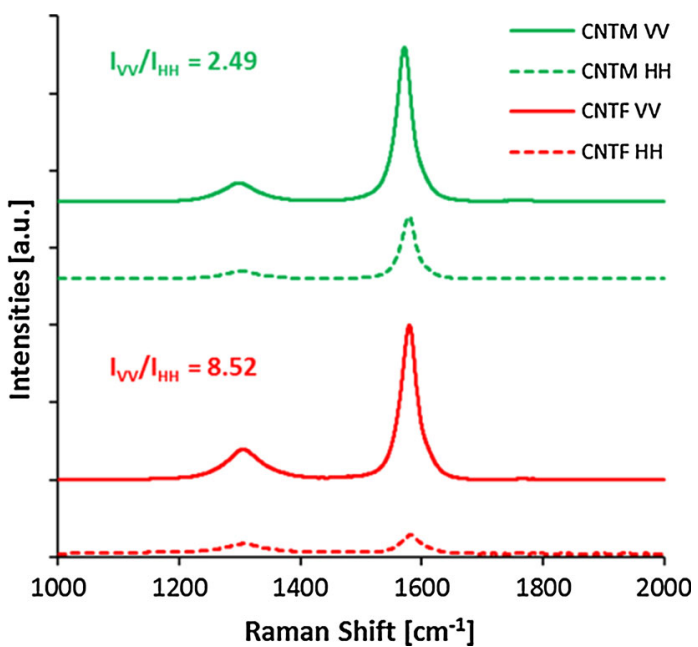

Figure 3 Characterization of CNT alignment in mats and fibres by polarized Raman spectroscopy. Raman spectra in VV and $\mathrm{HH}$ configuration, with the spinning direction/CNT bundle orientation being parallel to the $\mathrm{V}$ configuration of the incident beam, of CNT fibres (red) and b CNT mats (green). The vertical scaling is same for each curve, the curves have been displaced for clarity. Each of the plots is the average of ten measurements made over different parts of the sample.

base line as the minimum value data point, but it would be good to have further confirmation that this is correct. To this end, we carried out polarized Raman measurements of orientation measuring the relative intensities of the $G$ peak, with polarizer and parallel analyser aligned first with the fibre axis and then normal to it, known as VV and $\mathrm{HH}$ configuration. The data are shown in Fig. 3. It has been demonstrated [19] that when the direction of polarization is perpendicular to a single-wall nanotube, the intensity of the $G$ peak is too small to measure. The result of this is that measurements of the $G$ peak intensity of our samples in the $0^{\circ}$ and $90^{\circ}$ positions provide the ratio expected for the intensity at these two angles shown in the image analysis plots (Fig. 2c, f) and, thus, a check on the baseline choice for the FFT analysis of the micrographs.

The ratios are as follows:
$I_{0} / I_{90}$ mat sample
$2.85( \pm 0.5) / 1$-image analysis
(Fig. 2).
$2.49( \pm 0.1) / 1$-Raman (Fig. 3).
$I_{0} / I_{90}$ fibre sample $7.8( \pm 1.2) / 1$ —image analysis
(Fig. 2).
8.52 ( \pm 0.2$) / 1$-Raman (Fig. 3) 
Given the generous error bands on the estimation of the $I_{0}$ and $I_{90}$ values from the FFT analysis plots, we have not made any baseline adjustments which would have an effect on $\mathrm{H}$.

For post-spinning condensed mats, $I_{\mathrm{VV}} / I_{\mathrm{HH}}$ intensity ratio increased to $\sim 3.5$ which corroborates our observations of the effect of condensation on mechanical properties (supplementary materials, S4), where condensation enhanced lateral contacts between the CNT bundles as well as causes some local alignment.

\section{Nanocomposite structure}

Figure 4a shows a typical nanocomposite sample with dimensions of $40 \times 2 \times 0.2-0.8 \mathrm{~mm}$. 3D (Fig. $4 \mathrm{~b}, \mathrm{c}$ ), and 2D 'slice' images (Fig. 4d) reconstructed from X-ray micro-tomographic data show the uniform, highly anisotropic structure of a CNTF-composite with near perfectly aligned CNT fibres. The images confirm the absence of voids at its resolution limit of just below $1 \mu \mathrm{m}$, although the isolated small bright spots may indicate some sub-micrometer voids.
The weight fraction of the carbon nanotubes for each sample was measured by TGA according to the procedure described previously [12], and showed a high level of agreement with the known weight of nanotubes incorporated in each sample (see supplementary materials, S5), while the density of the nanotube bundles, in which the nanotubes are well aligned and packed, is calculated in supplementary materials, S6. We use TGA-based weight fractions for the data below.

Figure 5 shows that the calculated density values, while initially following the theoretical line, deviate for CNT weight fractions in excess of $40 \%$, as the measured density increasingly falls below the predicted line, a trend which we ascribe to an increasing percentage of voids in the composite. Complete penetration of the densely packed nanotube bundle network with resin appears to become more difficult as the CNT fibres are packed to greater densities in the mould. The data of Fig. 5 can thus be expressed as void content as in Fig. 6a below (for evaluation of the volume fraction and void content in composites refer to the supplementary materials, S7).
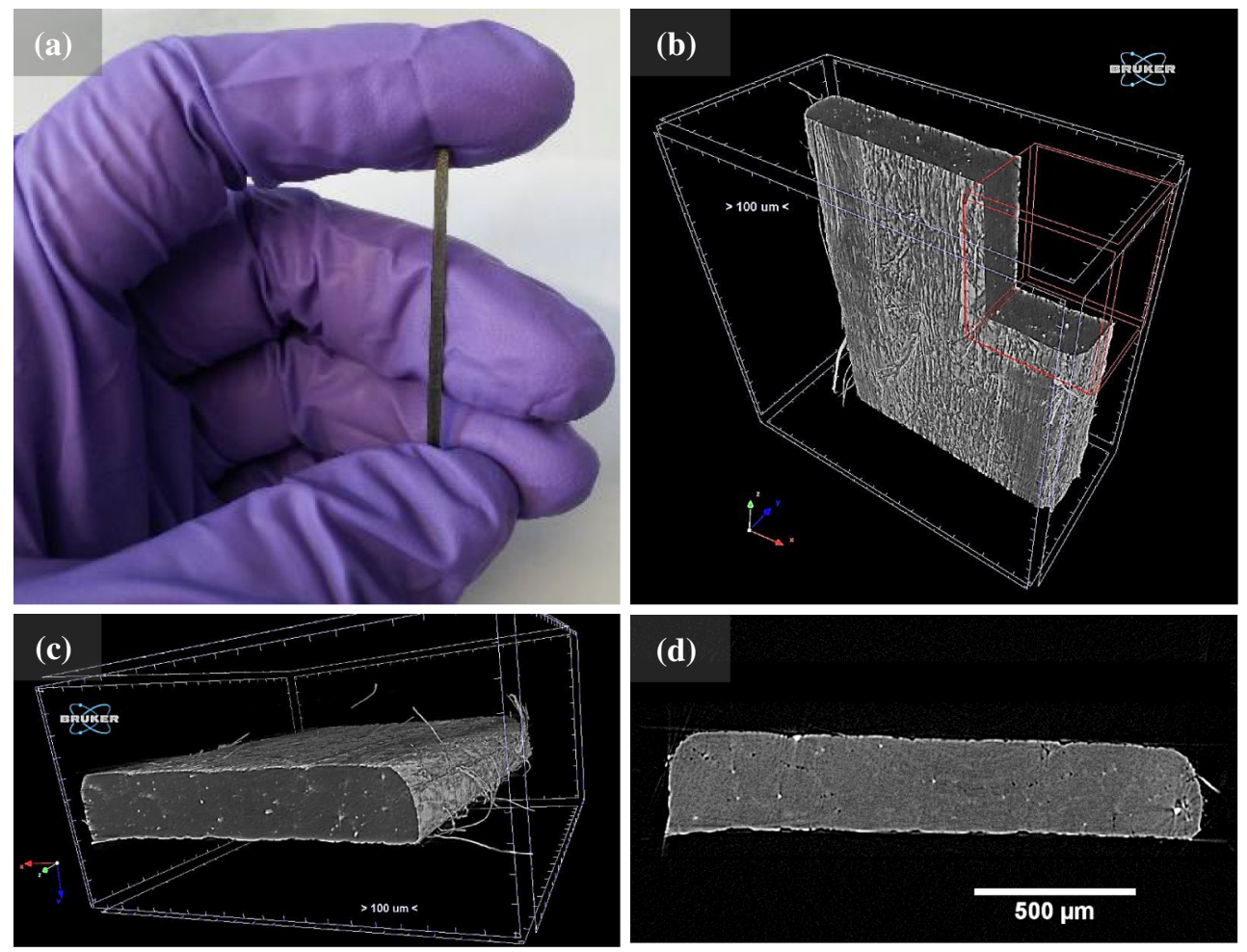

Figure 4 a CNTF-nanocomposite specimen, $\mathbf{b}$ and $\mathbf{c}$ X-ray tomography 3-D reconstruction, and $\mathbf{d}$ 2-D slice image of a representative CNTF-epoxy nanocomposite. Composites made from mats rather than CNT fibres show similar tomographic results. 


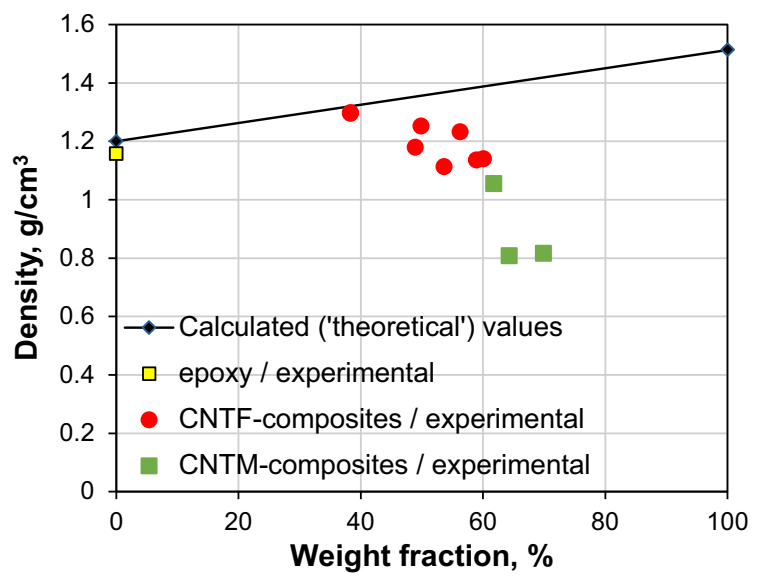

Figure 5 Comparison between theoretical and actual densities of the samples depending on weight fractions. The zero weight fraction is attributed to pure epoxy resin, while $100 \%$ corresponds to the density of pure CNTs. The black solid line represents the 'theoretical' density calculated from TGA-verified weight fractions and densities of the pure components for the 'ideal' composite without voids, with the density of the nanotube bundles being calculated as in (supplementary materials, S6). Coloured points show the actual density data determined from mass and volume measurements.

\section{Intrinsic porosity and infiltration}

The most common mechanisms for the formation of micro-voids or even macro-defects in the matrix are moisture absorption by resin components or prepregs on storing [20], release of volatile gases and water vapors in the curing process [21, 22], air-trapping and lay-up imperfections [20, 22, 23], or simply handling issues [24]. Voids of different shapes and sizes tend to occur primarily at the interface between the plies of prepregs, or between an individual reinforcement element and surrounding polymer matrix.

For CNT-composites, the void content becomes substantial on approaching CNT contents of $\sim 70 \%$ by weight (Fig. 6a).

SEM analysis of the cross section of a specimen with low filler content, thus cured in excess of epoxy (as reference only, not tested in this work), indicates easydetectable regions of pure epoxy matrix and very good fibre impregnation (Fig. 6b). This observation comes in full agreement with the previous studies from this group, where epoxy completely filled the gaps between CNT bundles in the fibres in composites with 17-26 [12] and $5-33 \%$ [13] weight fractions.

Interestingly, the cross sections of composites with higher CNT loadings show a higher void content located primarily inside the fibres as nano-scale pores, but not at the fibre-fibre or fibre-epoxy interface (Fig. 6c). Gaussian-fit histograms of the pore-size distribution indicate that for CNTF-nanocomposites, $70 \%$ of all pores are smaller than $250 \mathrm{~nm}^{2}$ and have an average area of $165 \mathrm{~nm}^{2}$ (Fig. 6e). This value is almost a half as that of the CNTM-composites, where an average pore area is $363 \mathrm{~nm}^{2}$ (Fig. 6f).

These data suggest that infiltration of the CNT fibres with resin is a key aspect of the nanocomposite material-which obviously does not occur for carbon fibre composites-and will have implications for the future optimization of the processing protocols.

Figure $6 \mathrm{c}$ also shows that at high-volume content of CNTs in the composite (we have used the volume fractions re-calculated from the experimentally verified weight fractions with the estimated CNT bundles density coupled with the fact that epoxy does not penetrate the bundles; the measured void fraction is also considered, supplementary materials, S5-S7), the fibres appear to be packed very densely with each other almost without visible layers of epoxy between them; however, this is not surprising. Considering a $1-\mathrm{m}$ length CNT fibre with 0.028 tex and diameter of about 7 $\mu \mathrm{m}$, its density simply calculated as a mass-to-volume ratio is only $0.73 \mathrm{~g} / \mathrm{cm}^{3}$. If considered density of the CNT bundles of about $1.66 \mathrm{~g} / \mathrm{cm}^{3}$, thus the void content within the CNT fibre itself appears to be approximately $50 \%$ (supplementary materials, S8), which is very close to what we observed in our previous work [14]. For practice, it means, that the volume of resin occluded with the fibre is equal to volume occupied by CNT bundles within the fibre. Hence, 30-40\% volume loading of CNTs is relative and equivalent to about 60-80 \% of the composite's total volume being occupied by the CNT fibres plus infiltrated resin. It confirms high actual packing density, thus we observe fibres packed very densely almost without visible regions of pure epoxy in between them. In contrast, our previous work $[12,13]$ and the sample repeated as a reference for the same weight fraction (Fig. 6b) have shown that for the composites containing 26-33\% wt carbon nanotubes, CNT fibres were not packed so tightly, with large regions of pure epoxy matrix between them (refer also to Fig. 3 in [12], and Figs. 1 and 2 in [13]).

\section{Behavior in tension}

Nanocomposites with similar volume fractions of CNT mats and fibres were tested to compare the 

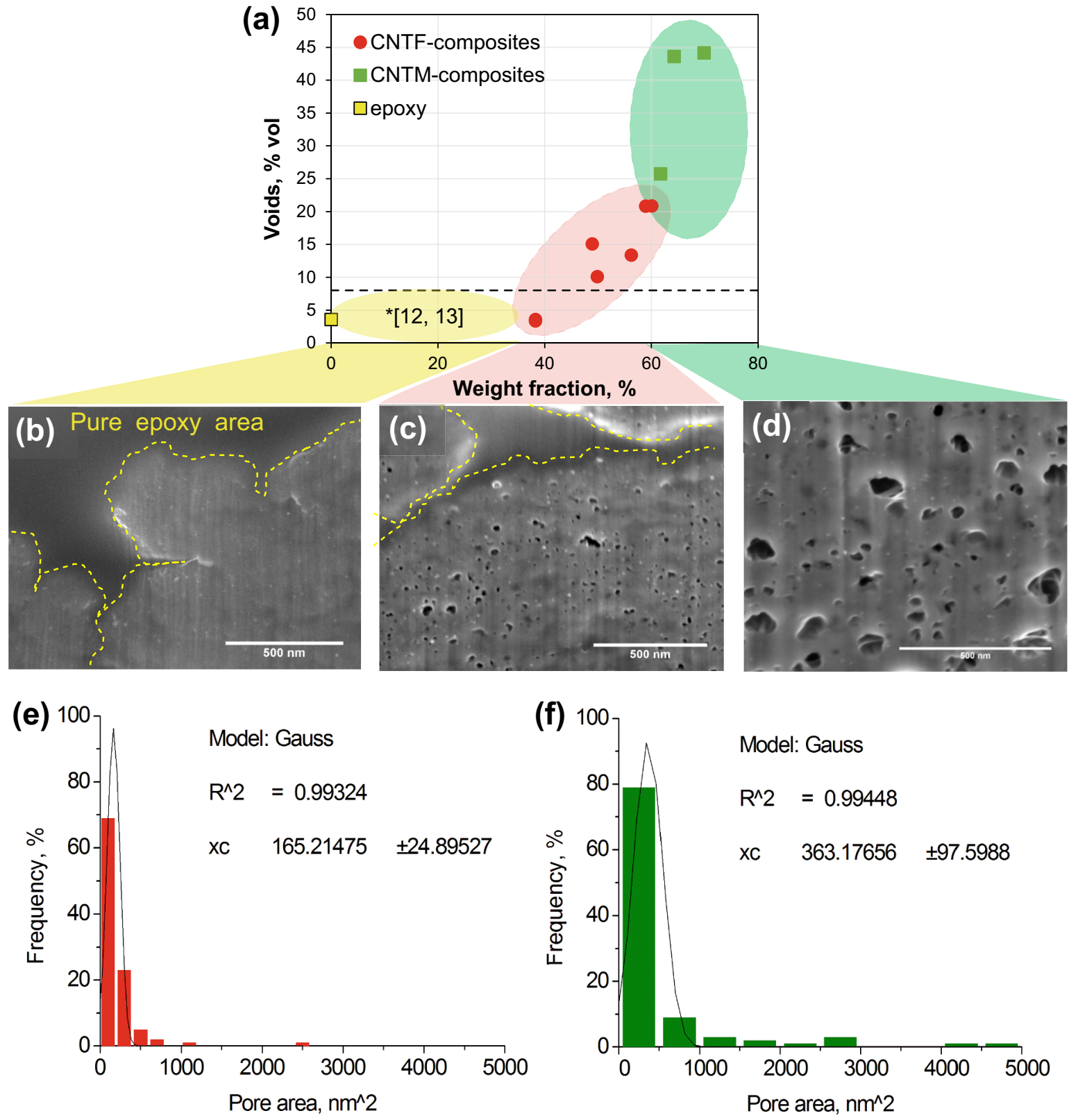

Figure 6 a Graph shows the general trend of void content increase (in \% vol) with increasing CNT content (in \% wt) in nanocomposites. The horizontal dashed black line (at $8 \%$ vol) represents a typical value of void content in carbon fibre-reinforced composites for an out-of-autoclave cure [21, 25] or cure in a vacuum bag with zero autoclave overpressure [26]. The yellow oval area is based on our previous results on low CNT-content

tensile properties of the two morphologies with pure epoxy matrix. Figure 7 shows representative stressstrain curves, and Table 1 summarizes data of tensile strength, stiffness, and elongation-to-break. For better comparison with the fibrous reinforcing elements, specific values of strength and stiffness of the

composites $[12,13]$. FIB-SEM cross sections of the nanocomposites filled with $\mathbf{b}$ and $\mathbf{c}$ CNT fibres and $\mathbf{d}$ CNT mats also show increasing void content at higher CNT loadings. Yellow dashed lines on images $\mathbf{b}$ and $\mathbf{c}$ delineate the infiltrated CNT fibres from inter-fibre regions of pure epoxy. $\mathbf{e}, \mathbf{f}$ show histograms of the poresize distribution determined from $\mathbf{c}$ and $\mathbf{d}$ images together with their Gaussian fits.

composites were also calculated in $\mathrm{N} /$ tex which is equivalent to the units of $\mathrm{GPa} /$ density (density in $\mathrm{g} / \mathrm{cm}^{3}$ ). The density in $\mathrm{g} / \mathrm{cm}^{3}$ is often expressed as Specific Gravity (SG) which is the density relative to that of water, while linear density is mass per unit length as tex $(\mathrm{g} / \mathrm{km})$. 


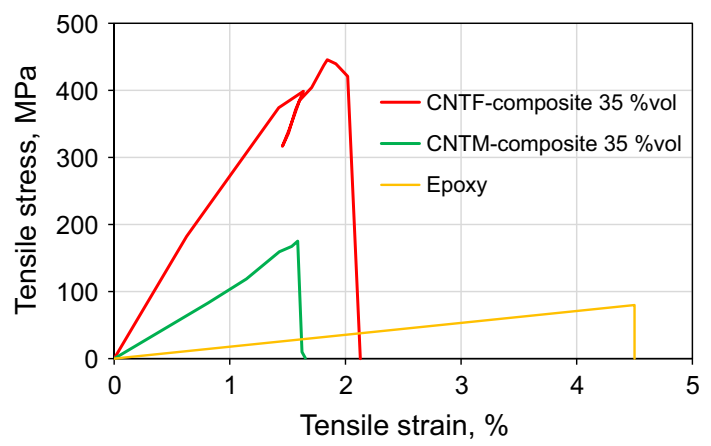

Figure 7 Representative tensile stress-strain curves for pure epoxy matrix and nanocomposites.

The improvement in strength and stiffness for the composite based on condensed CNT fibres is notable, being at least pro rata (linearly proportional to volume fraction) on the basis of the strength of individual fibres. For $35 \%$ volume loading, the specific tensile strength of the epoxy is enhanced a factor of $\sim 5$ and the specific modulus by a factor of $\sim 7.9$. The influence of uncondensed CNT mats as a reinforcing agent seems initially much less impressive, with enhancement factors of only $\sim 2.7$ and $\sim 4$, respectively. We ascribe the larger enhancement in the case of CNTF to the fact that the condensation considerably improves the degree of mutual alignment and closer contacts of the CNT bundles (supplementary materials, S4).

Less perfect alignment would explain the considerably greater extension to fracture, and the lower axial modulus, in the case of the composites based on CNT mats as opposed to fibres. Recent simulations of CNT vertical arrays show that the effective modulus can be reduced by several orders of magnitude due to $\mathrm{CNT}$ waviness [27, 28]. As-grown less-packed CNT arrays experience a larger local curvature and large reductions in effective modulus, while mechanically densified arrays are less curved and their stiffness is dominated by the low shear modulus of CNTs [28]. In respect to composite reinforcement, there have been several papers published from the early 2000s focused mostly on composites with low volume fractions (less than 25 vol\%) of short discrete nanotubes [29-31] or nanofibres [32]. It was shown that even slight nanotube curvature can significantly reduce the effective reinforcement potential when compared to straight nanotubes. The fractography of the tensile specimens after failure in Fig. 8a shows evidence of shear failure both between the fibres and within the fibres between the CNT bundles.

The fact that the tensile stress is applied to the external faces of the specimen in the grips means that the stress is only transmitted into the centre of the sample through shear, and the considerable mechanical anisotropy of the sample means that the load carried and thus extension of the individual fibres will vary with distance below the surface, with the outer fibres carrying the higher stress, at least close to the grips. This aspect has been studied and analysed in greater detail in respect of the as-spun CNT fibres by Gspann et al. [15]. It is possible that the transient load drop evident in the stress strain curve (Fig. 7) may correspond to the premature failure one of the outermost fibres, which did not trigger final failure.

For this testing regime, it appears that failure in shear between the fibres is a significant component of the total failure process and a consequence of the particular testing geometry. The fracture analysis as shown in Fig. $8 \mathrm{~b}$ and $\mathrm{c}$ bears evidence of nanotube bundle pull-out, even though each fibre is, of course, impregnated with epoxy.

The fracture morphology of the sample based on CNT mats rather than condensed fibres is shown in

Table 1 Axial tensile properties of the pure epoxy, CNT fibres, mats, and their composites

\begin{tabular}{|c|c|c|c|c|c|c|}
\hline \multirow[t]{2}{*}{ Sample } & \multirow[t]{2}{*}{ Volume fraction $(\%)^{\mathrm{a}}$} & \multicolumn{2}{|l|}{ Strength } & \multicolumn{2}{|l|}{ Stiffness } & \multirow[t]{2}{*}{ Elongation $(\%)$} \\
\hline & & $\mathrm{MPa}$ & $\mathrm{GPa} / \mathrm{SG}(\mathrm{N} / \mathrm{tex})$ & $\mathrm{GPa}$ & $\mathrm{GPa} / \mathrm{SG}(\mathrm{N} / \mathrm{tex})$ & \\
\hline Pure epoxy & 0 & $81.5 \pm 6.5$ & $0.076 \pm 0.006$ & $3.1 \pm 0.1$ & $2.9 \pm 0.1$ & $4.5 \pm 0.5$ \\
\hline CNTF-composite & 35 & $435 \pm 10$ & $0.390 \pm 0.009$ & $25.5 \pm 1$ & $22.9 \pm 0.9$ & $2.6 \pm 0.2$ \\
\hline CNTM-composite & 35 & $170 \pm 9.5$ & $0.206 \pm 0.011$ & $9.5 \pm 1$ & $11.5 \pm 1.2$ & $1.6+0.2$ \\
\hline CNT fibre 0.028 tex & 100 & - & $1.16 \pm 0.19$ & - & $55.7 \pm 11.8$ & $3.6 \pm 0.8$ \\
\hline $\begin{array}{l}\text { CNT mat } \\
0.964 \text { tex }\end{array}$ & 100 & - & $0.48 \pm 0.12$ & - & $7.6 \pm 1.5$ & $10 \pm 0.7$ \\
\hline
\end{tabular}

${ }^{\mathrm{a}}$ Volume fractions were calculated from the assumption that a composite is composed of volumes occupied by CNTs, epoxy matrix, and voids, thus including the void content added into the matrix (supplementary materials, S7) 

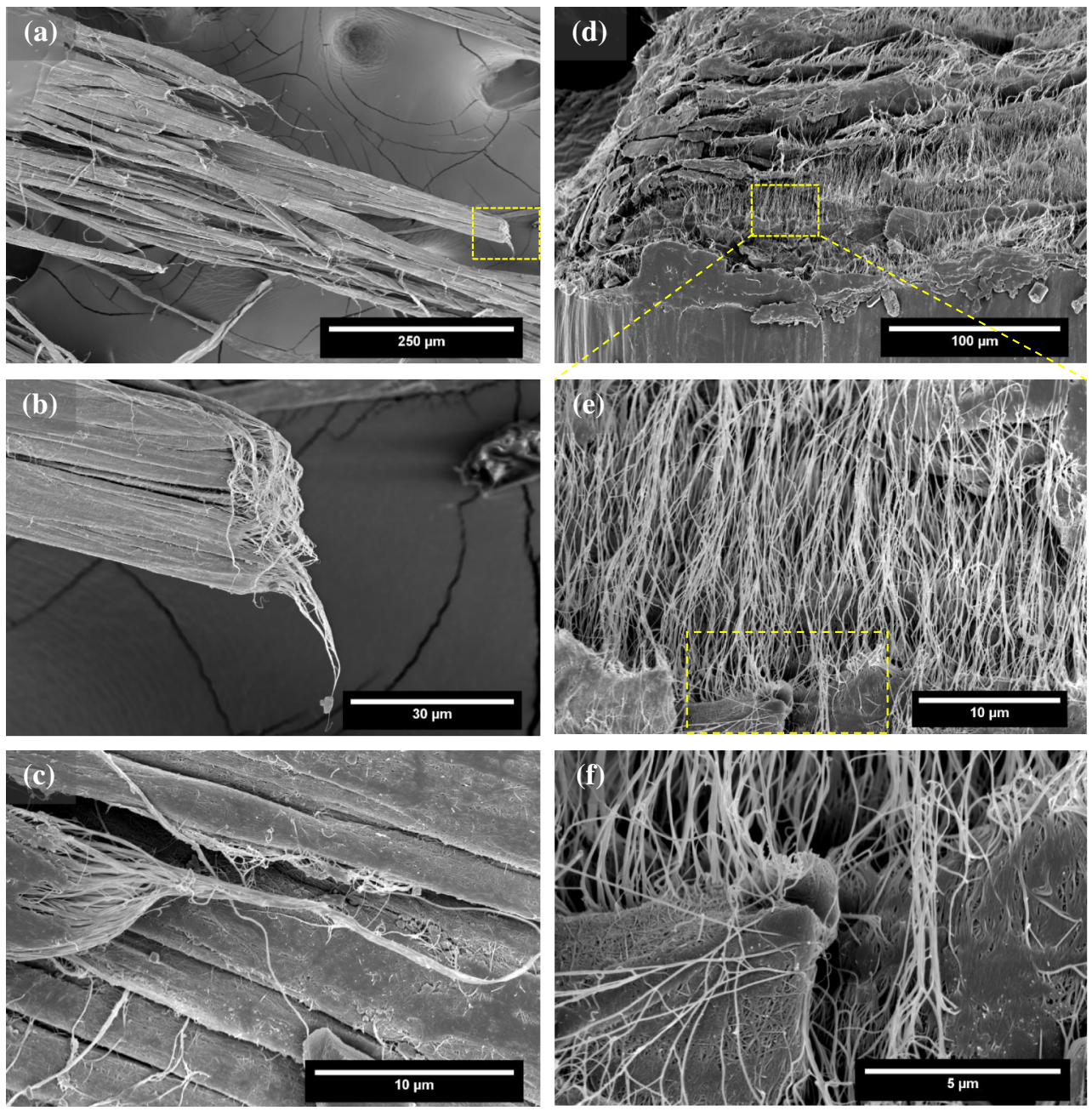

Figure 8 Fracture surfaces from tensile tests of the a-c CNTFand $\mathbf{d}-\mathbf{f}$ CNTM-composites. In the case of the composites based on condensed fibres, the sample shows evidence of failure in shear between the fibres a spacing of $\sim 5 \mu \mathrm{m}$. The inset of $\mathbf{a}$ is

Fig. 8d-f. It seems clear that the nanotube bundles have pulled-out from the fracture surface, although there is no evidence of them leaving holes behind in the epoxy matrix. However, in contrast to the CNTFcomposite, we did not observe delamination along the specimen long axis.

\section{Behavior in bending}

The flexural properties were determined using the standard test method according to ASTM D7264 developed for continuous fibre-reinforced polymeric composites and intended to evaluate longbeam flexural behavior. According to this method, the support span-to-thickness ratio should be chosen, such that failure occurs at the outer surface

magnified in $\mathbf{b}$ which shows the failure mode of several fibres, involving pull-out of the nanotube bundles. CNTM-composites show very considerable evidence of the pull-out of the nanotube bundles at the fracture surface in $\mathbf{d}$ and $\mathbf{e}$.

of a specimen, due to only the bending moment, which may appear as a crack on the tension surface, or as the local buckling on the compression side. In the case of highly anisotropic specimens where the flexural modulus is notably reduced by shear deformation, span-to-thickness ratios higher than the standard value of 32:1 are recommended. For testing, a span-to-thickness ratio of 40:1 was used, with a specimen length of about $20 \%$ longer than the support span distance.

The flexural strength-maximum stress at the outer surface at mid-span-and the flexural modulus of elasticity-ratio of stress to corresponding strain within the elastic limit-were calculated based on beam theory (please refer to ASTM D7264). 


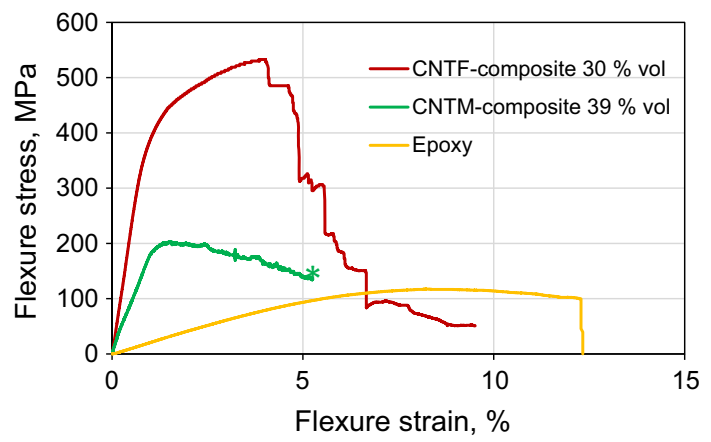

Figure 9 Representative bending stress-strain curves for pure epoxy matrix and nanocomposites. Note that the CNTM-composites test stopped due to reaching maximum rig deflection for the thinner sample used.

Representative strain-stress curves shown in Fig. 9 accompanied with data in Table 2 reveal distinctive bending behavior of the nanocomposites with the two morphologies.

The CNT fibre composites with a $30 \%$ volumetric loading showed increases in specific strength and stiffness by factors of $\sim 3.4$ and $\sim 18$, respectively. However, as with the tensile samples, the uncondensed CNT mat composites, even for a higher volumetric loading of $39 \%$, showed only minor enhancement in strength and stiffness with improvement factors of $\sim 1.5$ and $\sim 8$.

While in the tensile tests, the stress is transferred by shear from the gripped surfaces into the sample, in bending tests, stress transfer by shear provides the axial loading of the top (compression in this geometry) and bottom (tensile) surfaces, these stresses increasing from the mid plane towards each of the two surfaces.

Figure 10a, b is side views of the CNTF-composite which corresponds to the stress/strain curve of Fig. 9.

Tensile failure initiated on the face of maximum tensile stress and progressed towards the compressive face. There is also evidence of a degree of delamination parallel to the fibre axis, although whether this path is between or within the original fibres is not clear. Examination of the compressive face gives no indication of local buckling. Figure 10c is the view normal to the tension surface, showing the crack which initiated failure. At higher magnification, Fig. 10d, pulled-out nanotube bundles bridging the crack are clearly evident.

Composites based on nanotube mats (CNTM) showed a very different failure mode in bending. Microscopic examination of the compression face (top of side view in Fig. 11a) showed buckling by the surface layers 'arching' away from the original surface, with interlamellar shear and localized buckling, even more obvious in higher magnification (Fig. 11b).

The most striking aspect is that the CNTM-composites bear no evidence of tensile failure at all. In the bending rig with its maximum permissible strain of $5 \%$, the peak load was reached at around $1 \%$ strain. However, the relatively thin samples $(<0.5 \mathrm{~mm})$ never fractured. The deformation mode is, thus, a combination of compression and shear, with no tensile drawing or fracture apparent. The modest improvement in strength compared to the pure epoxy simply represents the onset of plastic failure due to buckling at the compressive face at $\sim 1 \%$ strain. There is, however, a considerable improvement in stiffness of the material for $39 \%$ volume fraction mats of a factor of 8 . The inclusion of the CNTs in the epoxy appears to have greatly enhanced the plasticity of the material in bending as well as its stiffness.

The buckling observed at the compressive face of the bending samples is considerable, and much of the yield flow seen in force deflection curves is associated with this form of compressive failure. Basically, both fibre and mats have essentially zero compressive strength until incorporated in the resin. Here, the restraining influence of the matrix delays the onset of Euler buckling. However, the difference between the fibre and mat composite samples, we could not find

Table 2 Flexural properties of the pure epoxy and CNT composites

\begin{tabular}{|c|c|c|c|c|c|c|}
\hline \multirow[t]{2}{*}{ Sample } & \multirow{2}{*}{$\begin{array}{l}\text { Volume } \\
\text { fraction }(\%)\end{array}$} & \multicolumn{2}{|c|}{ Flexural strength } & \multicolumn{2}{|c|}{ Flexural modulus } & \multirow{2}{*}{$\begin{array}{l}\text { Maximum surface } \\
\text { strain }(\%)\end{array}$} \\
\hline & & $\mathrm{MPa}$ & $\mathrm{GPa} / \mathrm{SG}(\mathrm{N} /$ tex $)$ & $\mathrm{GPa}$ & $\mathrm{GPa} / \mathrm{SG}(\mathrm{N} /$ tex $)$ & \\
\hline Pure epoxy & 0 & $124.5 \pm 4.5$ & $0.116 \pm 0.004$ & $2.1 \pm 0.1$ & $2.0 \pm 0.1$ & $12.7 \pm 1.3$ \\
\hline CNTF-composite & 30 & $514 \pm 30$ & $0.396 \pm 0.023$ & $47.3 \pm 2.8$ & $36.5 \pm 2.2$ & $4.5 \pm 0.5$ \\
\hline CNTM-composite $^{a}$ & 39 & $185 \pm 22$ & $0.172 \pm 0.021$ & $17.0 \pm 0.8$ & $15.8 \pm 0.7$ & $>5$ \\
\hline
\end{tabular}

${ }^{a}$ Note that the CNTM-composites test stopped due to reaching maximum rig deflection for the thinner sample used 

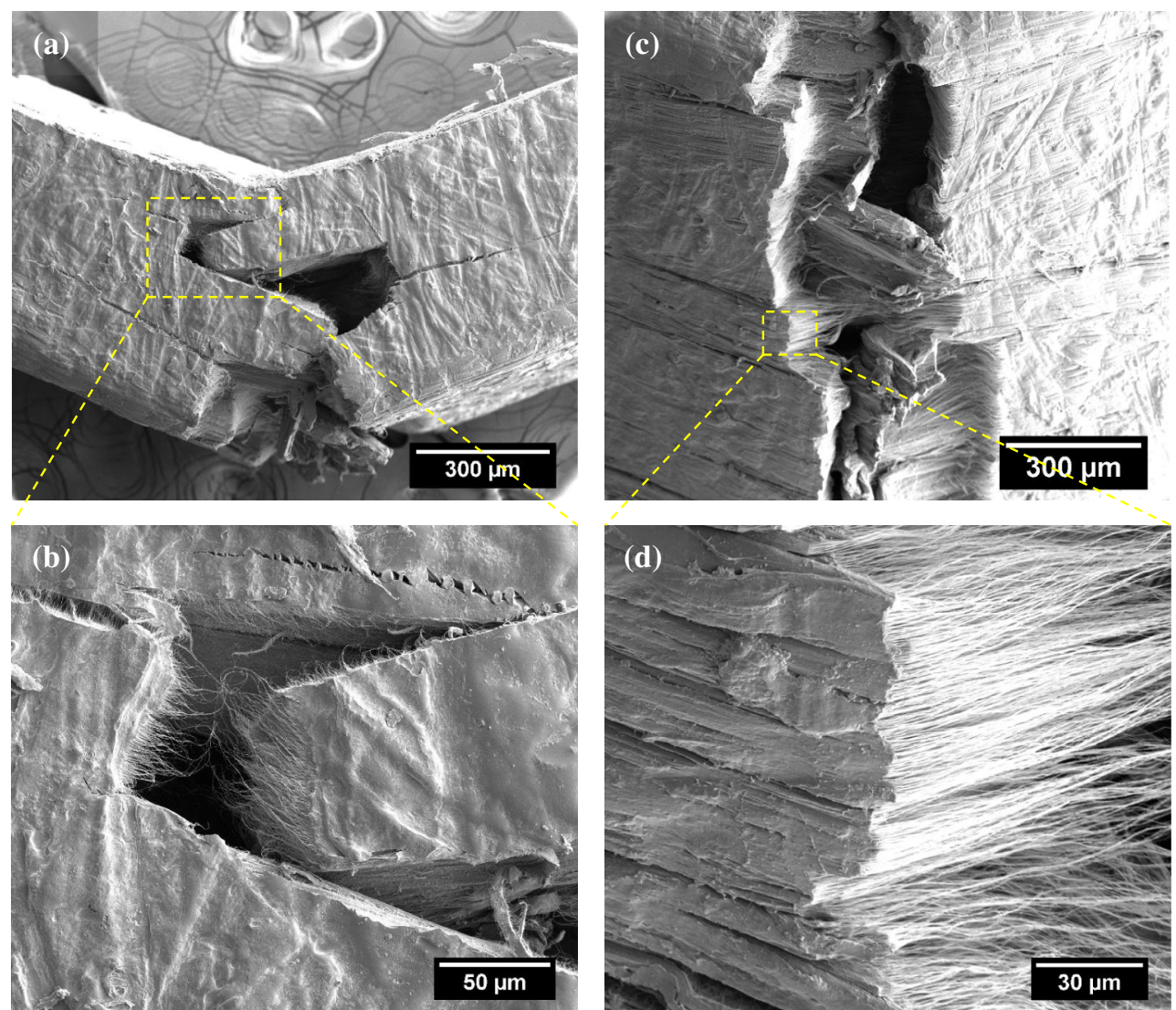

Figure 10 Bending-failure analysis of CNTF-composites: $\mathbf{a}, \mathbf{b}$ side views showing delamination, $\mathbf{c}$ fracture at the tensile surface of the sample with an enlarged region $\mathbf{d}$ displaying pulled-out nanotube bundles bridging the crack which has opened to $\sim 0.5 \mathrm{~mm}$.
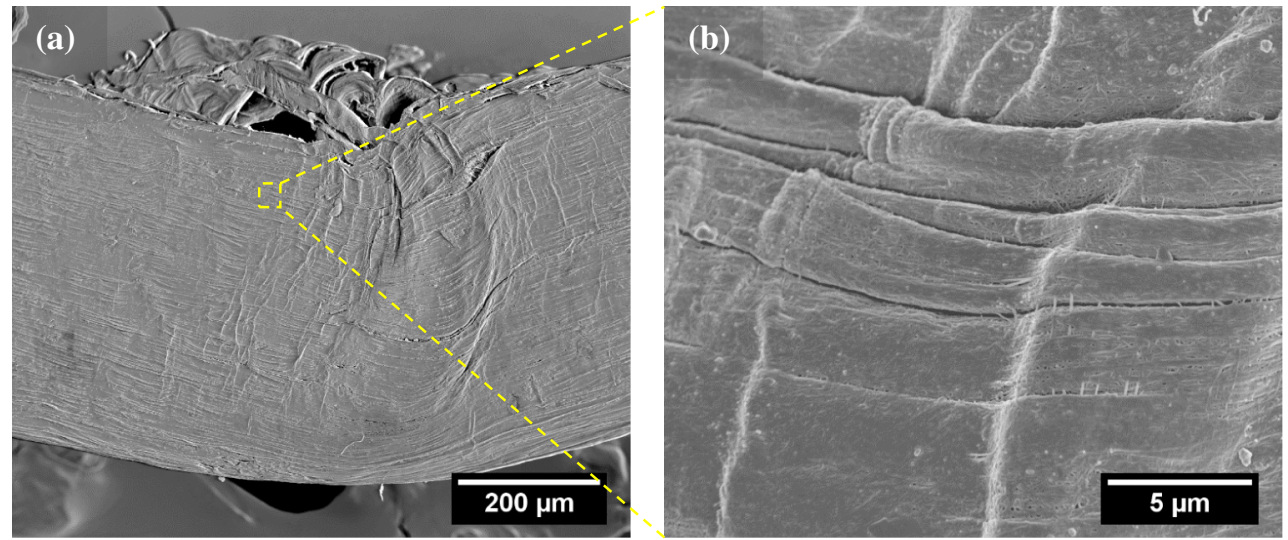

Figure 11 Bending-failure analysis of the CNTM-composite: a side view with distinct buckling where several layers were 'arching' away from the original surface under the loading, $\mathbf{b}$ enlarged image giving evidence for shear failures towards the compression side.

any evidence of buckling in the fibre composite, demonstrates that the additional mechanical coherence between the bundles, as achieved during the condensation stage of the fibre production, contributes to their considerably greater resistance to compressive buckling. In addition, it is possible that the improved quality of bundle alignment achieved in the fibres in it adds to resistance to buckling. 


\section{Discussion}

\section{Two areas of comparison}

In this section, we set out first to compare our results with those reported in the literature for high-volume fraction CNT-composites with epoxy matrix. We then compare the new data with the results for carbon fibre composite samples made using the same epoxy system and exactly the same techniques as for the CNT fibre composites.

General overview of recent results in high-volume fraction CNT-epoxy nanocomposites

Figure 12 summarizes the recent mechanical data in research on the epoxy nanocomposites filled with high amounts of different CNT assemblies: papers, sheets, vertically aligned arrays, and fibres. A tabulated summary, which also includes some data which could not be graphed on account of lack of any indication of volume fraction, is given in the supplementary materials, S9. For most of the data presented in Fig. 12, the values of volume fractions appear to have been calculated from the assumption that composites did not contain any voids or that their negative contribution to overall density was insignificant [24, 33].

The tensile strength and stiffness we reached in this work for the epoxy composites filled with CNT fibres (445 MPa, 26.5 GPa for $35 \%$ CNT volume fraction) are quite impressive, especially from the point that neither their CNT fibres nor their prepregs (prior to cure) were modified in any way, opening here the field for the future enhancement. For the CNTM-composites, in which there was no condensation applied, and thus a lower quality of alignment of the nanotube bundles with specimen axis, the strength was lower, at $180 \mathrm{MPa}$, and the stiffness also, at $10.5 \mathrm{GPa}$, demonstrating the importance of maximizing alignment quality. From that point of view, additional mechanical stretching of the CNT-epoxy prepregs can be an effective approach. For example, $5 \%$ stretching the resin-infused CNT arrays enhanced the tensile strength by 34 [10] or $51 \%$ [34], while $3 \%$ stretching the CNT sheets before resin impregnation has shown more than twice the strength for the composite filled with $35.8 \%$ vol of aligned CNTs [34].

The completeness of infiltration is influenced by the architecture and content of CNT assemblies.
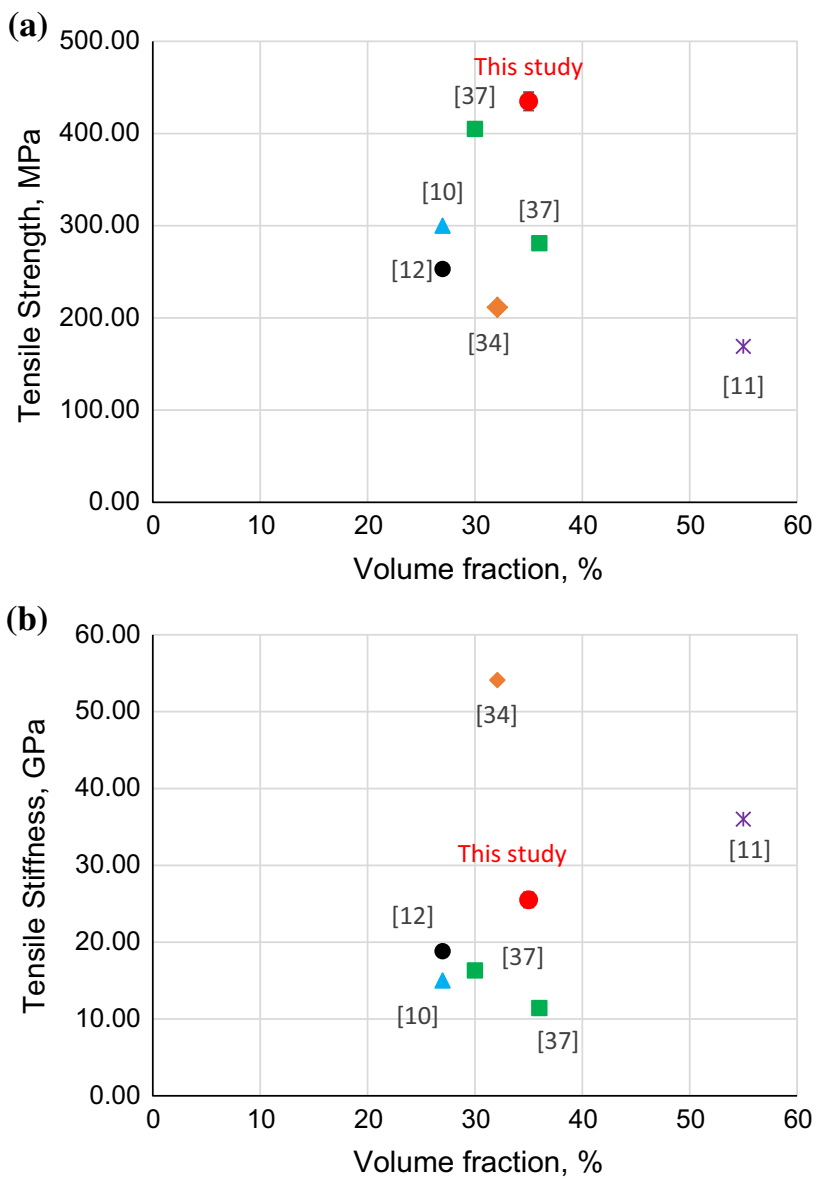

$\triangle$ Bradford et al [10]

- Nam et al [34]

* Mecklenburg et al [11]

- Mora et al [12]

Li et al [37]

This study

Figure 12 Comparison of $\mathbf{a}$ the tensile strength and $\mathbf{b}$ stiffness of the high-volume fraction CNT-epoxy composites.

Working with CNT films or mats made from randomly oriented CNT bundles, researchers are more often faced with incomplete infiltration and resultant porosity compared with studies based on highly aligned CNT assemblies. Lopes et al. [35] working with CNT sheets and felts have observed differences in the apparent density of their composites containing up to $20 \% \mathrm{wt}$ fraction of CNTs, the density values measured gravimetrically being 1-8\% lower than those calculated, with the implication of the presence of internal voids or porosity. Spitalsky et al. [36] observed that only in the case of composites with weight fractions of 7-8\% was the whole volume of pores inside MWCNT buckypapers completely filled by resin; while for some tested materials, they detected large voids which may reduce mechanical and thermal properties. In the most recent paper 
published by Li and coworkers [37], SEM analysis revealed an excessively porous structure of the epoxy composites filled with 20-54.2\% CNT films by weight, with low density and pore sizes in the range $72-77 \mathrm{~nm}$ being detected. It would seem that the pores compromised the composites' mechanical performance: for the composite with $45 \%$ wt fraction showed 405-MPa tensile strength, while the one with the highest CNT content-54.2\% wt-showed only 281-MPa strength.

Interestingly, for vertically aligned CNT arrays where nano-scale channels continue from the top to the bottom of the preform, immersion in epoxy, or its acetone solution gave particularly fast infiltration of the resin due to capillary driven wetting [24, 33]. Nanocomposites made in this way, with up to 20-27\% [10] by volume or, more recently, up to $67 \%$ by weight $(\sim 55 \%$ vol according to the weight-tovolume fraction conversion factor of 1.21 proposed by the authors) [11] have been reported without any porosity data. In the latter case [11], composites based on 'domino-pushed' CNT forests revealed axial strength of $170 \mathrm{MPa}$ and axial stiffness of $30 \mathrm{GPa}$. However, even in a case where all nanotubes are nearly straight and perfectly aligned, the infiltration process needs to be better understood. Cheng et al. [38] reported for the conventional RTM process, the maximum weight loading of super-aligned CNT sheets of $16.5 \%$ ( $10.6 \%$ by volume), while at $20 \%$ vol and above, the permeability of the CNT preform became too low, resulting in incomplete and nonuniform wetting even by a low viscosity resin $\left(50 \mathrm{cPa} \cdot \mathrm{s}\right.$ at $\left.60^{\circ} \mathrm{C}\right)$.

In the case of the CNT fibres, the resin penetration is related to the intrinsic packing density of the $\mathrm{CNT}$ bundles and is more difficult to achieve at higher CNT concentrations, at least in comparison with vertical CNT arrays or sparse CNT mats. Direct spinning from a CVD reactor generates yarn-like CNT fibres consisting of thousands of long nanotube bundles, showing their own levels of intrinsic entanglement and hierarchical organization. However, at the same time, an approach to enhance their packing density may have sense, as it was shown above that even the simple densification by acetone spraying may increase the tensile strength and stiffness of the as-spun materials. Some reported treatments, such as UV [39] or electron-beam irradiation [40], twisting, and infiltration with polymeric compounds [41-44] appear to affect lateral interactions between nanotube bundles, as well as molecular level couplings between nanotubes and polymer chains [43], thus amplifying the mechanical performance of CNT fibres or yarns [44] (supplementary materials, S10). Remembering the hierarchical structure of the CNT fibres, upon polymer infiltration, a fibre itself can be regarded as a nanostructural composite $[13,43]$ with $50-70 \%$ of a fibre occluded with a polymer depending on the fibre's internal porosity. However, the modified CNT fibres or yarns are still fibres or yarns physically, i.e., reinforcing materials, and objectively shall be compared directly with competitors-the conventional fibres-but not with their composite structures.

Indeed, our next generation of CNT fibres shows strengths of between 1.5 and $2.0 \mathrm{~N} /$ tex (as-synthesized, without post-treatments) [16], and future work will determine whether these improved fibres will translate to a $50 \%$ property enhancement in aligned high-volume fraction composites, and strengths of $\sim 1 \mathrm{GPa}$ and elastic moduli approaching $100 \mathrm{GPa}$ should be reasonable targets for future development of CNT-epoxy uniaxial composites.

\section{Comparison with similar composite samples made with the conventional carbon fibre}

CNT fibres, because of their yarn-like nature, are much more flexible in bending, and while this is an advantage in terms of toughness in handling operations, such as weaving, it does mean that it is more difficult to obtain high-quality mutual alignment by laying up in a mould, at least without applied axial tension, prior to infiltration of resin and subsequent compression. The poorer alignment also has a consequence less-efficient packing. To maintain a standardized process the tensile sample based on carbon fibre had a fibre volume fraction of $66 \%$ compared with around $35 \%$ for the CNT fibre sample. The carbon fibre composite specimen was also some $50 \%$ more dense $\left(1.41 \mathrm{~g} / \mathrm{cm}^{3}\right.$ compared with $1.09 \mathrm{~g} / \mathrm{cm}^{3}$ for the CNT fibre composite).

The graphical representation in Fig. 13 shows both strength and stiffness for the pure cured epoxy, the composite specimens, and the single fibres. They are put in terms of specific strength and moduli (GPa/density, with density in $\mathrm{g} / \mathrm{cm}^{3}$, or $\mathrm{N} /$ tex), so as to permit comparison with the values for the CNT assemblies, whether yarn-like fibre, or mat. The specific strength and stiffness of T300 of 3.5 and 

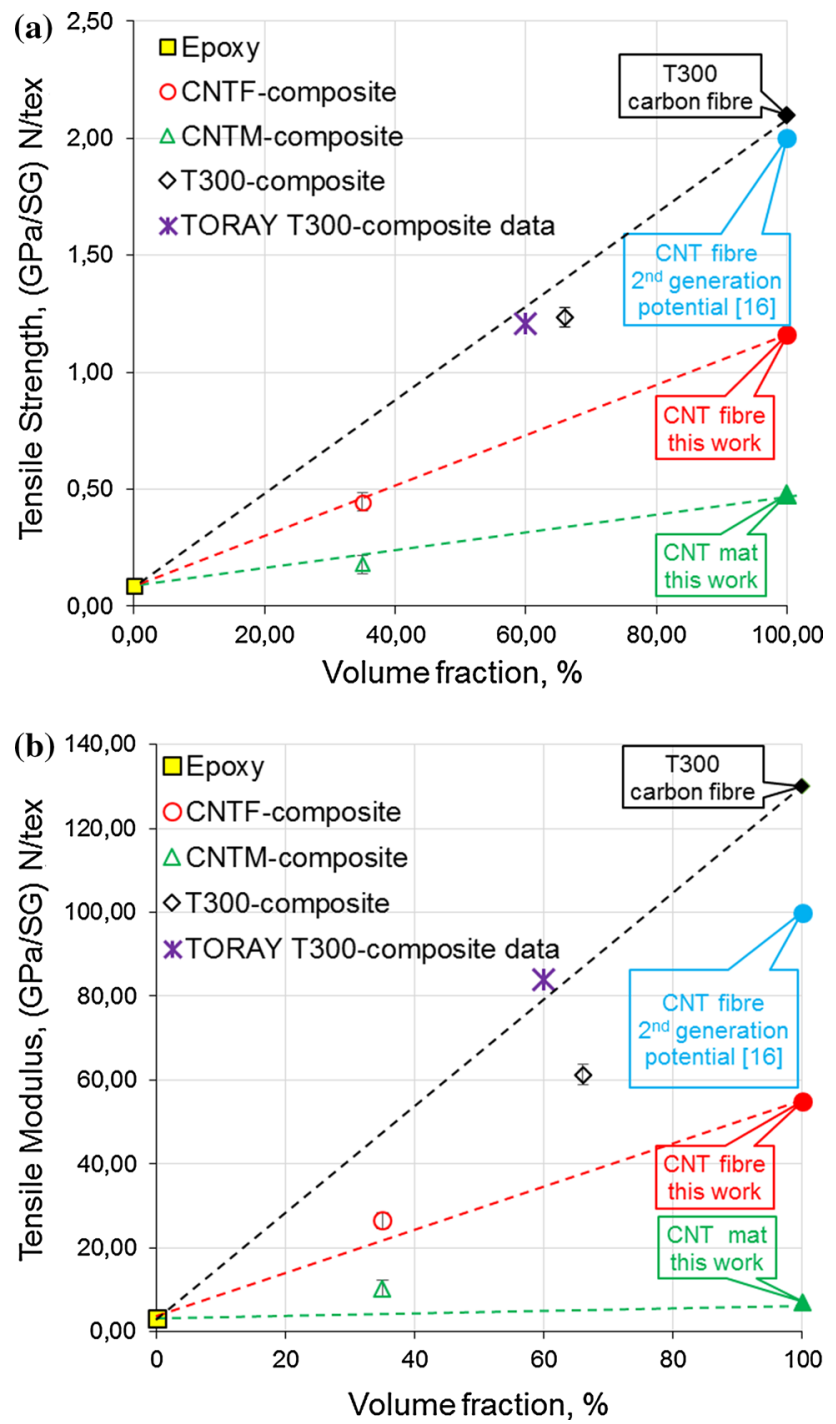

Figure 13 a Tensile strength and $\mathbf{b}$ stiffness of the CNTcomposites in comparison with T300-carbon fibre reinforcement. Note that the horizontal axis shows the volume fraction of the carbon component of the composite, where the value at $0 \%$ corresponds to pure matrix, and the values at $100 \%$ represent mechanical properties of the carbon reinforcing materials in the absence of any matrix (carbon fibre, CNT fibres, and CNT mat).

$230 \mathrm{GPa}$, respectively, were determined from published values ${ }^{2}$ of these parameters and a fibre density of $1.76 \mathrm{~g} / \mathrm{cm}^{3}$.

In each case, the values for the composites lie close to the pro rata line, although the value for T300-fibre composite stiffness seems significantly below. It is instructive, however, to plot also Toray's data ${ }^{2}$ for aligned T300-composites using their own epoxy resin

$\overline{2}$ TORAYCA T300 technical data sheet, No. CFA-001, www. torayusa.com.
(Toray 250F) which they have addressed to $60 \%$ vol fibre content. These values are shown as diagonal crosses on Fig. 13. They are somewhat higher than our own measurements, possibly due to the difference in processing (curing in a vacuum oven vs autoclave curing).

In general, it is interesting to note that our composites properties lie close to the pro rata line, just as in the case of the Toray published values for their aligned composite. Despite the very different nature of the CNT fibre, and especially in the case of the CNT aligned mat, their behavior in composites as far as tensile failure is concerned appears fairly normal. The data would imply that improvement in strength of the CNT fibres themselves-either through the synthesis optimization or post-treatments-should be a good route to improving the composite performance.

There are, however, two unique differences between carbon fibre and CNT fibre, one is the noticeable difference in production technology, and the other the yarn-like nature of the CNT fibres $(\sim 7 \mu \mathrm{m})$, which implies their different properties. In comparison with carbon fibre production, which relies on the special grades of polymer precursors and requires several technological steps, including high-temperature treatment at up to $3000{ }^{\circ} \mathrm{C}$ in the inert atmosphere ${ }^{3,4}$; synthesis of CNT fibres by this one-step process is more favorable in terms of energy and time consumption and related costs. The required synthesis temperature $\left(1300{ }^{\circ} \mathrm{C}\right)$ is similar to that of the conventional carbon black, ${ }^{5}$ which is one of the cheapest products produced in millions of tons and used in industry worldwide. In addition, the system can be potentially run using natural gas or $\mathrm{CO}_{2}{ }^{6}$ as the major carbon source, with the possibility of recycling both carrier gas and any unreacted hydrocarbon to reduce financial costs and make the production to be more environmentally friendly.

\footnotetext{
${ }^{3}$ McConnell, V. "The Making of Carbon Fiber", CompositesWorld, 19 December 2008.

http:/ / www.compositesworld.com/articles/the-making-ofcarbon-fiber.

${ }^{4}$ How is it made? Zoltek Toray Group. Commercial carbon fiber.

http://zoltek.com/carbonfiber/how-is-it-made/.

${ }^{5}$ Carbon black manufacturing, Asahi Carbon Co. Ltd http:// www.asahicarbon.co.jp/global_site/product/cb/manufactur ing.html.

${ }^{6}$ Carbon nanofibres made from $\mathrm{CO}_{2}$ in the air by Jonathan Webb.

http:/ / www.bbc.com/news/science-environment-33998697.
} 
In terms of properties, the light density of CNT fibres (around $1 \mathrm{~g} / \mathrm{cm}^{3}$ ) while considering the same specific strength and stiffness will eventually exceed carbon fibres $\left(1.7-1.8 \mathrm{~g} / \mathrm{cm}^{3}\right)$ for lightweight design and applications. Moreover, unlike the conventional carbon fibres, CNT fibres can be bent through very tight radii without apparent permanent damage, and can show excellent knot efficiency, as has been shown previously [4]. It means that in handling, there are no surface damage issues, and, moreover, it reveals the radically different fracture mechanism, discussed in the following section, suggests that the composites should be much more resistant to the propagation of transverse cracks or defects.

\section{Toughness of composites}

The toughness of a fibre, especially a high-performance one being assessed for ballistic applications, is often taken as the area under the stress-strain curve up to fracture. This assumes that the fracture when it occurs is brittle. However, such a measure, which might better be described as work of fracture, will give values which will be low for very ductile materials where failure is triggered by plastic instability (necking) or for yarns, such as CNT fibres where the instability is in shear.

Fracture toughness, defined as the resistance to the sudden propagation of a crack of length $a$ at a stress $\sigma$ to give a brittle fracture, is related to the product of the intrinsic materials parameters of stiffness $E$ and work to create crack surfaces $\gamma$. The value of $\gamma$ depends on energy absorption processes at the crack tip, and the square root of the product of the two parameters defines fracture toughness. We thus have two distinct measures of resistance to failure, one of which, the work of fracture, obtained by integration of the entire stress-strain curve up to the breaking point [45], will be dependent on sample geometry and testing mode. However, fracture energy determined in this way, though it cannot be interpreted as a true measure of toughness, does give a useful indication of fracture resistance. We have thus recorded these values expressed in $\mathrm{J} / \mathrm{g}$ for the range of samples tested (Fig. 14a). The composite sample based on T300-carbon fibre with a fibre volume fraction of $66 \%$ has also been tested for comparison (supplementary materials, S11). Measurement of fracture toughness requires larger samples than we have made so far, and involves the insertion of defects or notches of known geometries. It is instructive, however, to examine the failure mode in detail, especially that seen in subsidiary cracks which are frequently observed in sample broken in bending.

In the case of the traditional fibre composites, a major energy absorption mechanism is fibre pull-out. However, the fracture mechanism of CNT-composites appears to be essentially different. Where the composite is based on CNT fibres, there is no clear evidence of the fibres themselves pulling out of the matrix, mainly because the matrix penetrates the fibres filling much of the $\sim 50 \%$ of included interbundle nanovoids providing extremely strong 'keying', and thus, in effect, an unusually high-interface shear strength. [12]. However, there is very clear evidence of pull-out of nanotube bundles, if not individual nanotubes, from within the fibres (Fig. 14b, c). The subsidiary crack is shown at higher magnifications in Fig. 14c and d. The scale of the pullout process is nearly 100 times less than for the pullout of T300 fibres shown in Fig. 15b. In fact, the whole structure and its scale for the carbon nanotube composites are very reminiscent of crazing in polymeric glasses, where the fibrils consist of groups of extended polymeric chains. The diameter of the pulled-out CNT bundles is of the order of $40-50 \mathrm{~nm}$, very much in the range of those crazing fibrils of $10-40 \mathrm{~nm}$ seen in glassy polymers [46]. However, examination of Figs. 14d and 15a shows CNT bundles appear to be coated with matrix material which, in this case, has fractured before the core nanotube bundle, exposing the latter. It would appear that rather than fibre pull-out from the matrix, the occluded epoxy within the fibres participates with CNT bundles in forming the 'craze fibrils' (Fig. 15a).

Immediately, there arises the issue of ductility of the crosslinked epoxy resin. Making the reasonable assumption that a thickness of epoxy of a few tens of nanometers will be well below the critical crack length for this material, the question still remains as to the ability of such a material to flow without breaking a significant proportion of covalent bonds. We are also investigating the possibility that the presence of the nanotubes with their large accessible surface area interferes in some way with the epoxy crosslinking reaction. We will report on this study in due course. 

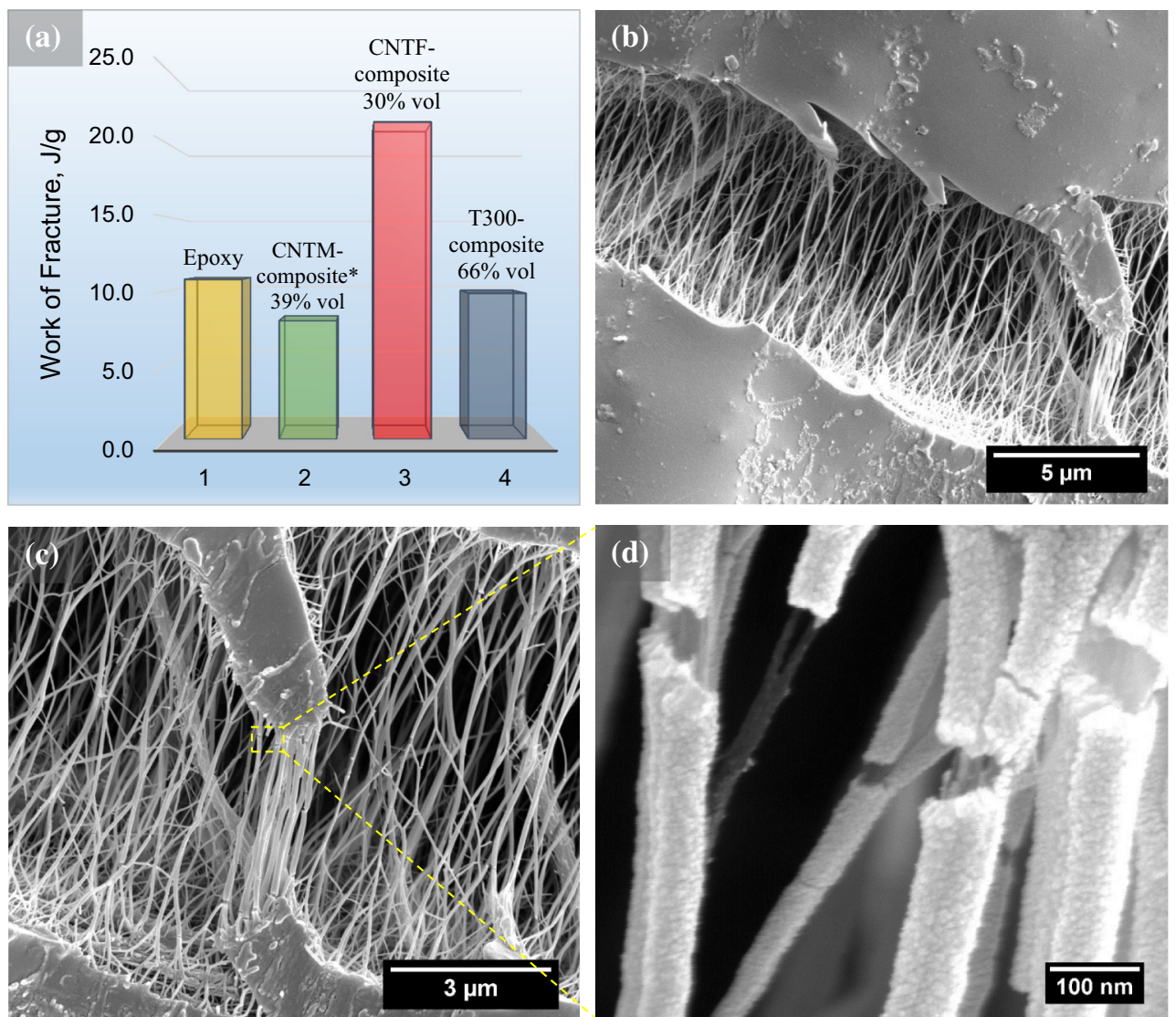

Figure 14 a Work of fracture diagram of the pure epoxy, CNTand T300-reinforced composites tested in three-point bending, and b-d show nanotube bundles "bridging" subsidiary cracks seen near to the tensile surface of a CNTF bend specimen. *Note that

the CNTM-composites test stopped due to reaching maximum rig deflection for the thinner sample used. The work of fracture is likely to be considerably greater than the $8 \mathrm{~J} / \mathrm{g}$ measured up to $5.5 \%$ strain

Figure 15 a Evidence of pullout of CNT bundles coated with epoxy matrix also participating in the pull-out process, and $\mathbf{b}$ failure of the T300-composite where carbon fibres rather delaminate and epoxy matrix breaks in a brittle manner.
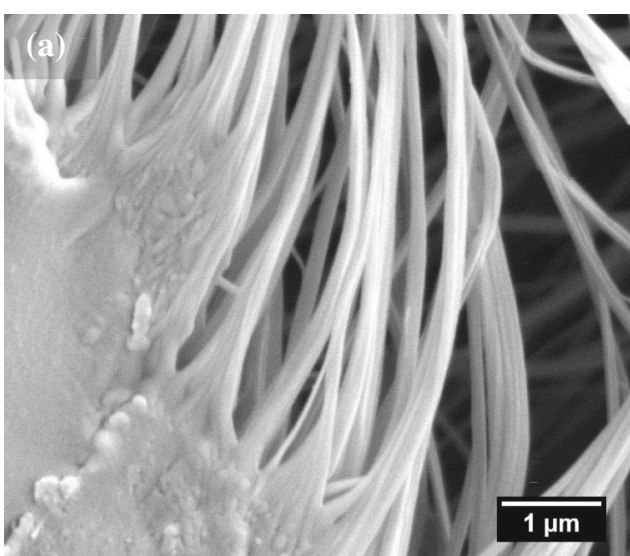

\section{Conclusions}

The work has shown that it is possible to fabricate aligned composites using carbon nanotubes which show mechanical enhancement in proportion to the volume fraction of the nanotubes added. The properties reported for samples using condensed CNT fibres are amongst the best seen for nanotube-epoxy composites. Aligned CNT mats, which show reduced tensile properties compared with the condensed 
fibres, produced corresponding weaker composites. In bending tests, the composites based on CNT mats, although not those based on fibres, showed buckling in the compressive regions. It is anticipated that recent improvement in the axial properties of CNT fibres and mats will be translated into yet better performance of their composites. Furthermore, the increasing concentration of voids at the highest loading fractions meant that this study was based on composite volume fractions of the order of $40 \%$ vol; however, future processing developments should overcome this restriction enabling samples with nanotube volume fractions similar to those obtainable in carbon fibre composites.

The failure mode of the CNT-composites is controlled by the pull-out of nanotube bundles; however, the SEM micrographs suggest that rather than this occurring at the interface with the epoxy matrix, some of the resin flows as a coating on the bundles. In bending, as cracks open up from several to hundreds of micrometers, they are bridged with pulled-out nanotube bundles of diameter of a few tens of $\mathrm{nm}$. In fact, the structures seen are extraordinarily reminiscent of crazing in glassy polymers. The CNT fibre itself shows remarkable toughness in bending, compared with carbon fibre, and it seems that its yarnlike nature also leads to rather different toughening mechanisms in aligned high-volume fraction composites, compared to composites based on the conventional high-performance fibres.

\section{Acknowledgements}

The authors wish to thank Jeronimo Terrones-Portas (University of Cambridge) for his valuable help with mould design; Jenny Shepherd (University of Cambridge) for technical help with X-ray micro-tomography analysis, Andrew Rayment (University of Cambridge) for guidance on mechanical tests; Patrick Kiley (University of Cambridge) for help with data analysis, Mark Whiter and Alex Baidak (Hexcel Composites Ltd., Duxford UK) for their suggestions and practical support; and Vaughan Dickinson (Huntsman Advanced Materials, Aerospace \& Industrial Composite, UK branch) for providing of epoxy resin for this research. The authors are also thankful to Dr James Elliott (University of Cambridge) for his interest and kind permission to accomplish this research within the Macromolecular Materials Laboratory.

\section{Compliance with ethical standards}

Ethical Statement This work was carried out with financial support of a Marie Curie Intra-European Human Mobility Fellowship Programme: "Project No. 251477: CNTF-composites" which is gratefully acknowledged. However, the contents reflect only the authors' views and not the views of the University or the European Commission. Alan Windle is a director of Q-Flo Ltd., in which he has a shareholding, and consults in the general field of Materials Science.

Open Access This article is distributed under the terms of the Creative Commons Attribution 4.0 International License (http://creativecommons.org/ licenses/by/4.0/), which permits unrestricted use, distribution, and reproduction in any medium, provided you give appropriate credit to the original author(s) and the source, provide a link to the Creative Commons license, and indicate if changes were made.

Electronic supplementary material: The online version of this article (doi:10.1007/s10853-016-0228-6) contains supplementary material, which is available to authorized users.

\section{References}

[1] Behabtu N, Young CC, Tsentalovich DE, Kleinerman O, Wang X, Ma AWK, Bengio EA, Waarbeek RF, Jong JJ, Hoogerwerf RE, Fairchild SB, Ferguson JB, Maruyama B, Kono J, Talmon Y, Cohen Y, Otto MJ, Pasquali M (2013) Strong, light, multifunctional fibers of carbon nanotubes with ultrahigh conductivity. Science 339(6116):182-186. doi:10. 1126/science. 1228061

[2] Jiang C, Saha A, Young CC, Hashim DP, Ramirez CE, Ajayan PM, Pasquali M, Marti AA (2014) Macroscopic nanotube fibers spun from single-walled carbon nanotube polyelectrolytes. ACS Nano 8(9):9107-9112. doi:10.1021/ nn502552q

[3] Zhang M, Atkinson KR, Baughman RH (2004) Multifunctional carbon nanotube yarns by downsizing an ancient technology. Science 306(5700):1358-1361. doi:10.1126/sci ence. 1104276

[4] Vilatela JJ, Windle AH (2010) Yarn-like carbon nanotube fibers. Adv Mater 22(44):4959-4963. doi:10.1002/adma. 201002131 
[5] Aleman B, Reguero V, Mas B, Vilatela JJ (2015) Strong carbon nanotube fibers by drawing inspiration from polymer fiber spinning. ACS Nano 9(7):7392-7398. doi:10.1021/ acsnano. 5b02408

[6] Xu F, Sadrzadeh A, Xu Z, Yakobson BI (2013) Can carbon nanotube fibers achieve the ultimate conductivity?-coupled-mode analysis for electron transport through the carbon nanotube contact. J Appl Phys 114:063714. doi:10.1063/1. 4818308

[7] Lekawa-Raus A, Patmore J, Kurzepa L, Bulmer J, Koziol K (2014) Electrical properties of carbon nanotube based fibers and their future use in electrical wiring. Adv Funct Mater 24:3661-3682. doi:10.1002/adfm.201303716

[8] Koziol K, Vilatela J, Moisala A, Motta M, Cunniff P, Sennett M, Windle A (2007) High-performance carbon nanotube fiber. Science 318:1892-1895. doi:10.1126/science.1147635

[9] Windle A (2014) Carbon nanotube fibres: science and technology transfer. Nanoscience and technology for mankind. Humana Press, Allahabad

[10] Bradford PD, Wang X, Zhao HB, Maria JP, Jia QX, Zhu YT (2010) A novel approach to fabricate high volume fraction nanocomposites with long aligned carbon nanotubes. Compos Sci Technol 70(13):1980-1985. doi:10.1016/j.compsci tech.2010.07.020

[11] Mecklenburg M, Mizushima D, Ohtake N, Bauhofer W, Fiedler B, Schulte K (2015) On the manufacturing and electrical and mechanical properties of ultra-high wt $\%$ fraction aligned MWCNT and randomly oriented CNT epoxy composites. Carbon 91:275-290. doi:10.1016/j.carbon.2015. 04.085

[12] Mora RJ, Vilatela JJ, Windle AH (2009) Properties of composites of carbon nanotube fibres. Compos Sci Technol 69(10):1558-1563. doi:10.1016/j.compscitech.2008.11.038

[13] Vilatela JJ, Khare R, Windle AH (2012) The hierarchical structure and properties of multifunctional carbon nanotube fibre composites. Carbon 50(3):1227-1234. doi:10.1016/j. carbon.2011.10.040

[14] Qiu J, Terrones J, Vilatela JJ, Vickers ME, Elliott JA, Windle AH (2013) Liquid infiltration into carbon nanotube fibers: effect on structure and electrical properties. ACS Nano 7(10):8412-8422. doi:10.1021/nn401337m

[15] Gspann TS, Montinaro N, Pantano A, Elliott JA, Windle AH (2015) Mechanical properties of carbon nanotube fibres: St Venant's principle at the limit and the role of imperfections. Carbon 93:1021-1033. doi:10.1016/j.carbon.2015.05.065

[16] Gspann TS, Small FR, Windle AH (2014) Spinning of carbon nanotube fibres using the floating catalyst high temperature route: purity issues and the critical role of sulphur. Faraday Discuss 173:47-65. doi:10.1039/c4fd00066h
[17] Ayres CE, Jha BS, Meredith H, Bowman JR, Bowlin GL, Henderson SC et al (2008) Measuring fiber alignment in electrospun scaffolds: a user's guide to the 2D fast Fourier transform approach. J Biomater Sci Polym Ed 19(5):603-621. doi:10.1163/156856208784089643

[18] Stein IY, Wardle BL (2013) Coordination number model to quantify packing morphology of aligned nanowire arrays. Phys Chem Chem Phys 15:4033-4040. doi:10.1039/ c3cp43762k

[19] Duesberg GS, Loa I, Burghard M, Syassen K, Roth S (2000) Polarized Raman spectroscopy on isolated single-wall carbon nanotubes. Phys Rev Lett 85(25):5436-5439. doi:10. 1103/PhysRevLett.85.5436

[20] Liu L, Zhang BM, Wang DF, Wu ZJ (2006) Effects of cure cycles on void content and mechanical properties of composite laminates. Compos Struct 73(3):303-309. doi:10. 1016/j.compstruct.2005.02.001

[21] Grunenfelder LK, Centea T, Hubert P, Nutt SR (2013) Effect of room-temperature out-time on tow impregnation in an out-of-autoclave prepreg. Compos Part A Appl Sci 45:119-126. doi:10.1016/j.compositesa.2012.10.001

[22] Tavares SS, Michaud V, Manson JAE (2009) Through thickness air permeability of prepregs during cure. Compos Part A Appl Sci 40(10):1587-1596. doi:10.1016/j.composi tesa.2009.07.004

[23] Huang H, Talreja R (2005) Effects of void geometry on elastic properties of unidirectional fiber reinforced composites. Compos Sci Technol 65(13):1964-1981. doi:10.1016/j. compscitech.2005.02.019

[24] Wardle BL, Saito DS, Garcia EJ, Hart AJ, de Villoria RG, Verploegen EA (2008) Fabrication and characterization of ultralight-volume-fraction aligned carbon nanotube-polymer composites. Adv Mater 20(14):2707-2714. doi:10.1002/ adma.20080029524

[25] Centea T, Hubert P (2011) Measuring the impregnation of an out-of-autoclave prepreg by micro-CT. Compos Sci Technol 71(5):593-599. doi:10.1016/j.compscitech.2010.12.009

[26] Zhu HY, Li DH, Zhang DX, Wu BC, Chen YY (2009) Influence of voids on interlaminar shear strength of carbon/ epoxy fabric laminates. Trans Nonferr Metal Soc 19:S470 S475

[27] Ginga NJ, Chen W, Sitaraman SK (2014) Waviness reduces effective modulus of carbon nanotube forests by several orders of magnitude. Carbon 66:57-66. doi:10.1016/j.car bon.2013.08.042

[28] Stein IY, Lewis DJ, Wardle BL (2015) Aligned carbon nanotube array stiffness from stochastic three-dimensional morphology. Nanoscale 7:19426-19431. doi:10.1039/ C5NR06436H 
[29] Fisher FT, Bradshaw RD, Brinson LC (2002) Effects of nanotube waviness on the modulus of nanotube-reinforced polymers. Appl Phys Lett 80(24):4647-4649. doi:10.1063/1. 1487900

[30] Fisher FT, Bradshaw RD, Brinson LC (2003) Fiber waviness in nanotube-reinforced polymer composites-I: modulus predictions using effective nanotube propeties. Comp Sci Technol 63:1689-1703. doi:10.1016/S0266-3538(03)00069-1

[31] Rafiee R (2013) Influence of carbon waviness on the stiffness reduction of CNT/polymer composites. Comp Struct 97:304-309. doi:10.1016/j.compstruct.2012.10.028

[32] Varischetti J, Jang JS, Gibson RF, Suhr J (2013) Effect of filler waviness and orientation on the damping behavior of CNF-reinforced epoxy composites. J Mat Sci 48:832-840. doi:10.1007/s10853-012-6803-6

[33] Cebeci H, de Villoria RG, Hart AJ, Wardle BL (2009) Multifunctional properties of high volume fraction aligned carbon nanotube polymer composites with controlled morphology. Compos Sci Technol 69(15-16):2649-2656. doi:10.1016/j.compscitech.2009.08.006

[34] Nam TH, Goto K, Nakayama H, Oshima K, Premalal V, Shimamura Y, Inoue Y, Naito K, Kobayashi S (2014) Effects of stretching on mechanical properties of aligned multiwalled carbon nanotube/epoxy composites. Compos Part A Appl Sci 64:194-202. doi:10.1016/j.compositesa.2014.05. 013

[35] Lopes PE, van Hattum F, Pereira CMC, Novoa PJRO, Forero S, Hepp F, Pambaguian L (2010) High CNT content composites with CNT Buckypaper and epoxy resin matrix: impregnation behaviour composite production and characterization. Compos Struct 92(6):1291-1298. doi:10.1016/j. compstruct.2009.11.003

[36] Spitalsky Z, Tsoukleri G, Tasis D, Krontiras C, Georga SN, Galiotis C (2009) High volume fraction carbon nanotubeepoxy composites. Nanotechnology 20(40):405702. doi:10. 1088/0957-4484/20/40/405702

[37] Li M, Wang Z, Liu Q, Wang S, Gu Y, Li Y, Zhang Z (2015) Carbon nanotube film/epoxy composites with high strength and toughness. Polym Compos. doi:10.1002/pc.23617

[38] Cheng QF, Wang JP, Wen JJ, Liu CH, Jiang KL, Li QQ, Fan SS (2010) Carbon nanotube/epoxy composites fabricated by resin transfer molding. Carbon 48(1):260-266. doi:10.1016/ j.carbon.2009.09.014

[39] Boncel S, Sundaram RM, Windle AH, Koziol KKK (2011) Enhancement of the mechanical properties of directly spun CNT fibers by chemical treatment. ACS Nano 5(12):9339-9344. doi:10.1021/nn202685x

[40] Miller SG, Williams TS, Baker JS, Sola F, Lebion-Colon M, McCorkle LS, Wilmoth NG, Gaier J, Chen M, Meador MA (2014) Increased tensile strength of carbon nanotube yarns and sheets through chemical modification and electron beam irradiation. ACS Appl Mater Interfaces 6(9):6120-6126. doi:10.1021/am4058277

[41] Filleter T, Espinosa HD (2013) Multi-scale mechanical improvement produced in carbon nanotube fibers by irradiation cross-linking. Carbon 56:1-11. doi:10.1016/j.carbon. 2012.12.016

[42] Naraghi M, Filleter T, Moravsky A, Locascio M, Loutfy RO, Espinosa HD (2010) A multiscale study of high performance double-walled nanotube-polymer fibers. ACS Nano 4(11):6463-6476. doi:10.1021/nn101404u

[43] Ma W, Liu L, Zhang Z, Yang R, Liu G, Zhang T, An X, Yi X, Ren Y, Niu Z, Li J, Dong H, Zhou W, Ajayan PM, Xie S (2009) High-strength composite fibers: realizing true potential of carbon nanotubes in polymer matrix through continuous reticulate architecture and molecular level couplings. Nano Lett 9(8):2855-2861. doi:10.1021/n1901035v

[44] Shimamura Y, Oshima K, Tohgo K, Fujii T, Shirasu K, Yamamoto G, Hashida T, Goto K, Ogasawara T, Naito K, Nakano T, Inoue Y (2014) Tensile mechanical properties of carbon nanotube/epoxy composite fabricated by pultrusion of carbon nanotube spun yarn preform. Compos A Appl Sci Manuf 62:32-38. doi:10.1016/j.compositesa.2014.03.011

[45] Lachman N, Wagner HD (2010) Correlation between interfacial molecular structure and mechanics in CNT/epoxy nano-composites. Compos Part A Appl Sci 41(9):1093-1098. doi:10.1016/j.compositesa.2009.08.023

[46] Bucknall CB (1977) Toughened plastics. Applied Science Publishers Ltd, London, UK 